\title{
On the impacts of phytoplankton-derived organic matter on the properties of the primary marine aerosol - Part 2: Composition, hygroscopicity and cloud condensation activity
}

\author{
E. Fuentes ${ }^{1}$, H. Coe ${ }^{1}$, D. Green ${ }^{2}$, and G. McFiggans ${ }^{1}$ \\ ${ }^{1}$ Centre for Atmospheric Sciences, School of Earth, Atmospheric and Environmental Sciences, Manchester M13 9PL, UK \\ ${ }^{2}$ Scottish Association for Marine Science, Oban, UK
}

Received: 4 October 2010 - Published in Atmos. Chem. Phys. Discuss.: 4 November 2010

Revised: 3 March 2011 - Accepted: 15 March 2011 - Published: 18 March 2011

\begin{abstract}
The effect of nanogel colloidal and dissolved organic matter $<0.2 \mu \mathrm{m}$, secreted by marine biota, on the hygroscopic growth and droplet activation behaviour of the primary marine aerosol was studied. Seawater proxies were prepared by the combination of artificial seawater devoid of marine organics and natural seawater enriched in organic exudate released by laboratory-grown phytoplankton cultures, as described in a companion paper. The primary aerosol was produced by bubble bursting, using a plunging multijet system as an aerosol generator.

The aerosol generated from seawater proxies enriched with marine exudate presented organic volume fractions on the order of $8-37 \%$, as derived by applying a simple mixing rule. The hygroscopic growth and cloud condensation nuclei $(\mathrm{CCN})$ activity of the marine organics-enriched particles where 9-17\% and 5-24\% lower, respectively, than those of the aerosol produced from artificial seawater devoid of exudate. Experiments in a companion paper indicated that the cloud nuclei formation could be enhanced in diatom bloom areas because of the increase in the primary particle production induced by marine organics. The experiments in the present study, however, indicate that the impacts of such an enhancement would be counteracted by the reduction in the $\mathrm{CCN}$ activity of the primary particles enriched in marine organics.

The extent of the effect of the biogenic matter on the particle behaviour was dependent on the seawater organic concentration and type of algal exudate. Aerosol produced from seawater proxies containing diatomaceous exudate presented higher hydrophobicity and lower CCN activity than those en-
\end{abstract}

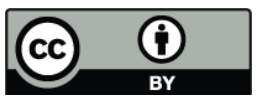

Correspondence to: Gordon McFiggans (g.mcfiggans@manchester.ac.uk) riched with nanoplankton exudate. The organic fraction of the particles was found to correlate with the seawater organic concentration, without observing saturation of the particle organic mass fraction even for unrealistically high organic matter concentration in seawater. These findings are indicative that discrepancies on the composition of the primary aerosol between different studies could partly be explained by the difference in the nature and concentration of the organic matter in the source seawater employed.

Consistently across the experiments, theoretical analysis based on the Köhler model predicted a reduction in the primary marine aerosol $\mathrm{CCN}$ activity upon the incorporation of marine organics into the particle composition. This effect is consequence of the replacement of small inorganic sea salt molecules by large molar mass organic molecules, together with a moderate suppression of the surface tension at the point of activation of $5-0.5 \%$, which leads to a dominance of the reduction in the dissolved solute in the Raoult term.

\section{Introduction}

In a companion paper, an experimental study on the influence of marine biogenic matter on the submicron primary marine aerosol production has been presented (Fuentes et al., 2010b). The present paper extends this experimental study to describe the influence of organic matter produced by phytoplankton on the hygroscopicity and $\mathrm{CCN}$ behaviour of the primary marine aerosol.

Chemical analysis of marine particles collected in field experiments has provided evidence for the presence of significant concentrations of organic matter in the submicron marine aerosol (Hoffman and Duce, 1977; Novakov et al.,

Published by Copernicus Publications on behalf of the European Geosciences Union. 
1997; Middlebrook et al., 1998; Putaud et al., 2000; Cavalli et al., 2004). The organic content of the atmospheric marine aerosol has been found to follow a seasonal pattern, characterised by organic fractions accounting for up to $63 \%$ of the submicron aerosol dry mass during warm periods (O'Dowd et al., 2004). Although it is postulated that the presence of organic matter released by marine biota might affect marine aerosol properties, little is known on the effect of these organics on the behaviour of aerosols produced in areas of high biological activity.

The chemical composition of the marine aerosol determines its hygroscopic properties, which in turn influences its ability to scatter light and to form cloud condensation nuclei (Moore et al., 2008). Analysis of the chemical composition of the primary marine aerosol generated by bubble bursting from natural seawater has shown high organic mass fractions in the submicron size region (up to $\sim 80 \%$ for particles sizes $\sim 125-250 \mathrm{~nm}$ ), with increasing enrichment with decreasing particle size (Facchini et al., 2008; Keene et al., 2007). The majority of this organic matter was found to be water insoluble, consistent with the organic matter found in the atmospheric marine aerosol composition during periods of high biological activity (Facchini et al., 2008; O'Dowd et al., 2004). In contrast, studies of the hygroscopic behaviour of submicron primary aerosol generated from unfiltered natural seawater by bubble bursting have reported hygroscopic growth suppressions $<10 \%$ with respect to pure $\mathrm{NaCl}$ (Sellegri et al., 2008; Modini et al., 2009). This hygroscopic growth implies low organic volume fractions $(<10 \%)$, in contrast with the high fractions reported in preceding studies on the chemical composition of the primary marine aerosol produced by bubble bursting (Keene et al., 2007; Facchini et al., 2008). It has been postulated that discrepancies in the organic enrichment of primary particles generated in different studies is related not only to the amount of organics present in the seawater samples, but also to the composition and surface-active properties of the organic matter in the source seawater (Modini et al., 2009; Fuentes et al., 2010b). Different bubble bursting generation mechanisms have been observed to affect the organic enrichment and the influence of organics on the hygroscopic and cloud condensation behaviour of the particles (Fuentes et al., 2010a).

Parameterisations predicting particle number production as a function of temperature (Mårtensson et al., 2003), organic matter content (Fuentes et al., 2010b), modal sizes (O’Dowd et al., 2008) and organic mass fraction (Vignati et al., 2010) are currently applied to estimate the marine particle production and composition on a global scale (Vignati et al., 2010). A large uncertainty in the determination of marine particle distribution is implicit in these model predictions, due to the large discrepancy in the estimation of the particle organic fraction between different studies and to the fact that the composition of marine particles is generally modelled by extrapolating regional relationships between particle composition and biological activity to a global scale (Vignati et al.,
2010). In order to reduce the uncertainty in global scale predictions further research is needed to understand the underlying processes leading to differences in the particle organic fraction obtained in different laboratory studies, asses the validity of current formulations to be applied globally and establish solid correlations between biological activity and marine aerosol composition.

The role of oceanic phytoplankton in affecting the marine cloud condensation nuclei $(\mathrm{CCN})$ formation remains largely unknown. Analysis of remotely sensed data on regions of different biological activity have indicated an enhanced cloud formation activity over algal bloom areas with respect to regions of low productivity (Meskhidze and Nenes, 2006). This finding has been attributed to changes in the chemical composition and size distribution of the condensation nuclei (Meskhidze and Nenes, 2006). Several mechanisms by which marine biota can modify marine cloud formation have been proposed. These hypothetical mechanisms are related to the impact of the primary organic matter released by marine biota on the particles' CCN activity (O'Dowd et al., 2004) and to the formation of secondary aerosol from the oxidation of phytoplankton-produced volatile compounds, like dimethylsulfide (Charlson et al., 1987) and non methane hydrocarbons (Meskhidze and Nenes, 2006). Different modeling approaches have been proposed to explore the potential effects of different phytoplankton-derived compounds in order to infer viable mechanisms through which the organic matter can affect marine cloud nuclei formation (Meskhidze and Nenes, 2006; O'Dowd et al., 2004).

Since the marine organic matter exhibits surface-active properties, it has been postulated that it may play a role in determining the marine particles' cloud activation behaviour through its effect on the surface tension of the aqueous droplets (O'Dowd et al., 2004). A number of experimental and modeling studies have addressed the effect of surfactants on the cloud condensation activity of aerosols containing diverse inorganic solutes ( $\mathrm{Li}$ et al., 1998; Kristensson, 2010; Moore et al., 2008). According to Li et al. (1998) the reduction in the surface tension by surfactant molecules suppresses the critical supersaturation through the Kelvin effect; however, the replacement of small inorganic solute molecules by large surfactant molecules can cause a reduction in the dissolved solute in the Raoult term of the Köhler equation and lead to an increase in the critical supersaturation. It has been argued that the $\mathrm{CCN}$ activity of atmospheric aerosols depends on the organic proxy employed and that a reduction in the critical supersaturation could be produced by surface-active compounds representative of atmospheric organic matter (Facchini et al., 2001).

The aim of this work is to elucidate the extent to which the organic matter secreted by marine biota, incorporated in the particle phase through the bubble bursting process, can effectively influence the hygroscopic and cloud condensation behaviour of the primary marine aerosol. Cultures of microalgae strains representative of oceanic species were grown 
in order to produce natural bioexudate. This material was employed to prepare seawater proxies for the production of primary aerosol by means of a multi-plunging water jet generator. Measurements of the CCN activity and hygroscopicity properties of the laboratory-produced aerosols were conducted and compared with blanks performed with artificial seawater devoid of algal exudate. Together with the experimental analysis, the classical Köhler theory was applied to reconcile the hygroscopic and cloud condensation activity measurements and to provide insight into the factors leading to the observed cloud condensation activity behaviour.

\section{Experimental methods}

\subsection{Sample preparation, aerosol generation and aerosol characterization}

Artificial seawater was prepared from analytical grade salts and deionised water following the method described by Kester et al. (1967), so that the ionic mass ratios of $\mathrm{Na}^{+}$, $\mathrm{Cl}^{-}, \mathrm{Mg}^{2+}, \mathrm{HCO}_{3}^{-}$and $\mathrm{SO}_{4}^{2-}$ were comparable to those in real seawater. Natural seawater samples enriched with organics released by algal laboratory cultures were subjected to $0.2 \mu \mathrm{m}$ filtration in order to remove bacteria and avoid biodegradation of the organic matter released by the marine algae during the aerosol experiments (Fuentes et al., 2010b).

The organic matter in the size range $<0.2 \mu \mathrm{m}$, herein referred as $\mathrm{OC}_{<0.2 \mu \mathrm{m}}$, comprises colloidal micro- and nanogels along with truly dissolved organic carbon (Verdugo et al., 2004). There exist experimental evidence that marine colloidal matter can present sizes below $0.2 \mu \mathrm{m}$ and that this colloidal fraction can be even more abundant that colloids of higher size range (Wells and Goldberg, 1993). In addition, it is suggested that aggregation of marine colloidal matter $<0.2 \mu \mathrm{m}$ is an important mechanism for the formation of aggregates in the supermicron size range (Wells and Goldberg , 1993). Facchini et al. (2008) found that most of the organic fraction in the primary aerosol submicron size distribution was water insoluble (WIOC) and that the composition of this fraction presented a similar signature to that of organic matter in the size range $0.1-10 \mu \mathrm{m}$, extracted from seawater. The origin of WIOC in the primary aerosol has been attributed to the colloidal organic matter secreted by phytoplanckton (Facchini et al., 2008). The samples used in the present study, although in a lower size range than the organic matter extracted for analysis by Facchini et al. (2008), contain an important part of the colloidal and microgel fraction of marine organic matter (Verdugo et al., 2004). Thus, the organic material in the samples employed in this study can contribute to the insoluble organic fraction observed in the submicron primary aerosol composition (Facchini et al., 2008). It should be noted that although the term DOC (dissolved organic carbon) is generally applied to organic carbon with size $<0.5-0.7 \mu \mathrm{m}$ obtained after filtration, this term is defined as a function of size, not solubility, and thus, it is inappropriate for defining the organic carbon pool in this size range, where compounds of different solubility coexist (Verdugo et al., 2004).

Two different methods were applied to prepare seawater proxies using the produced phytoplankton exudate. In the bulk mixing method, seawater solutions containing a single algal exudate type were prepared at organic carbon concentrations of the order of those found in surface waters collected during an algal bloom in the equatorial Atlantic Ocean $(92-451 \mu \mathrm{M} \mathrm{OC}<0.2 \mu \mathrm{m}$; Chla $=0.81-4.69 \mu \mathrm{g} / \mathrm{L}$ ) (Fuentes et al., 2010b). High concentrations of $\mathrm{OC}_{<0.5-0.7 \mu \mathrm{m}}$ have also been found in studies by Sugimura and Suzuki (1988) (up to $320 \mu \mathrm{M}$ ) and Martin and Fitzwater (1992) (up to $230 \mu \mathrm{M}$ ) in surface waters from the Pacific Ocean. The experiments conducted are therefore only representative of the primary particle production occurring in algal blooms. For the preparation of the samples, artificial seawater devoid of exudate and aliquots of the stock solution of natural seawater enriched with organics were mixed to obtain the selected $\mathrm{OC}_{<0.2 \mu \mathrm{m}}$ concentration. Some experiments with unrealistic high concentration of organic matter $(>910 \mu \mathrm{M})$ were also conducted in order to study whether the particles organic fraction reached saturation. Tables 1 and 2 list the different algal exudate employed and seawater proxies prepared for the experiments. With the monolayer method, the effect of organic microlayers on the particle production was investigated. Solid phase extraction (C-18 Sep-Pak SPE cartridges) was applied to extract the hydrophobic matter contained in $2 \mathrm{ml}$ of the aqueous exudates, by using $10 \mathrm{~mL}$ of a $2: 1$ volumetric mixture of chloroform and ethanol as extraction solvent. The solvent extracted samples were dried out and redissolved in chloroform and spread dropwise on the surface of artificial seawater contained into the bubble tank.

Bubble-bursting aerosols were produced by the impingement of water jets generated by means of a water recirculation system in the centre of a PTFE tank (Fig. 1). The experimental conditions for the generation of the proxy marine aerosol are described in Fuentes et al. (2010b).

A continuous flow CCN counter (Droplet Measurement Technologies) combined with a Vienna designed DMA and a particle counter TSI 3010 CPC were employed to characterise the aerosol cloud condensation activity. The DMA was used to generate monodisperse aerosol in the size range between $40 \mathrm{~nm}$ and $100 \mathrm{~nm}$ dry diameter. These particles were directed in parallel to the CPC and CCN counters. The sample flow in the CCN counter was $0.5 \mathrm{lpm}$ and it was operated at different supersaturations in the range between $0.07 \%$ and $1 \%$ for each particle size. Deliquescence curves of 40 $100 \mathrm{~nm}$ dry diameter particles were measured by means of a Hygroscopicity Tandem Differential Mobility Analyzer (HTDMA), following the methodology described in Fuentes et al. (2010a). The calibration and quality assurance procedures carried out for the two instruments are described in Good et al. (2010). 
Table 1. Algal species employed for the production of exudate and organic carbon content $\left(\mathrm{OC}_{<0.2 \mu \mathrm{m}}\right)$ of seawater proxies prepared with a single algal exudate.

\begin{tabular}{llccc}
\hline Algal specie & Algal group & \multicolumn{3}{c}{$\mathrm{OC}_{<0.2 \mu \mathrm{m}}(\mu \mathrm{M})$} \\
\hline Thalassiosira rotula CCAP 1085/13 & Diatom & 175 & 300 & 512 \\
Chaetoceros sp. CCAP 1010/12 & Diatom & 175 & 300 & 512 \\
Emiliania huxleyi AC475 & PNAN, Coccolithophore & 175 & 512 & 2171 \\
Phaeocystis cf. globosa LY1 & PNAN, Prymnesiophyte & 175 & 512 & 910 \\
\hline
\end{tabular}

Table 2. Contribution of single algal exudates to the organic carbon content of seawater proxies prepared with exudate mixtures (total $\left.\mathrm{OC}_{<0.2 \mu \mathrm{m}}=512 \mu \mathrm{M}\right)$.

\begin{tabular}{lllll}
\hline \multirow{2}{*}{ Mixture sample } & T. rotula & Chaetoceros & E. huxleyi & Phaeocystis \\
\hline TRotulamix & $256(50 \%)$ & $85.33(16.67 \%)$ & $85.33(16.67 \%)$ & $85.33(16.67 \%)$ \\
Chaetmix & $85.33(16.67 \%)$ & $256(50 \%)$ & $85.33(16.67 \%)$ & $85.33(16.67 \%)$ \\
EHuxmix & $85.33(16.67 \%)$ & $85.33(16.67 \%)$ & $256(50 \%)$ & $85.33(16.67 \%)$ \\
Phaeomix & $85.33(16.67 \%)$ & $85.33(16.67 \%)$ & $85.33(16.67 \%)$ & $256(50 \%)$ \\
\hline
\end{tabular}

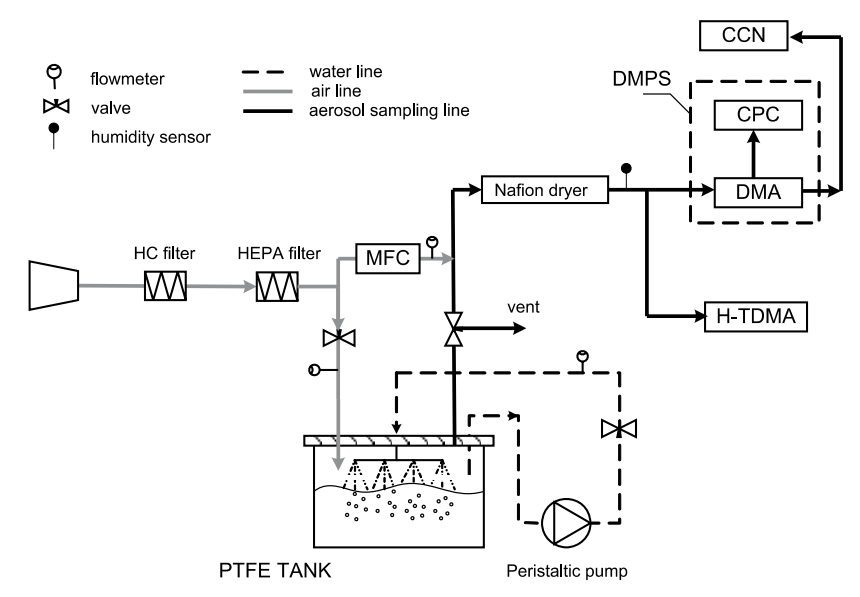

Fig. 1. Experimental set-up for aerosol size distribution (Fuentes et al., 2010b), hygroscopicity and CCN experiments. DMPS = differential mobility particle sizer, DMA=differential mobility analyzer, $\mathrm{CCN}=$ cloud condensation nuclei counter, $\mathrm{CPC}=$ particle counter, $\mathrm{H}-\mathrm{TDMA}=$ Hygroscopic-tandem differential mobility analyzer, $\mathrm{MFC}=$ mass flow controller.

\subsection{Surface tension measurements}

Compression isotherms of films of marine organics extracted by solid phase extraction were measured with a non-porous PTFE trough (KSV Minitrough, $273 \mathrm{~cm}^{2}$ surface area) provided with a platinum Wilhelmy plate film balance. Solid phase extraction (C-18 Sep-Pak SPE cartridges) was applied to extract the hydrophobic fraction of $2 \mathrm{ml}$ aqueous exudate samples, by using $10 \mathrm{~mL}$ of a 2:1 volumetric mixture of chloroform and ethanol as extraction solvent. The solvent extracted samples were dried out, redissolved with chloro- form:ethanol solution and deposited dropwise on the surface of water contained in the trough, to form a monolayer. Compression isotherms were recorded at a symmetric compression rate of $10 \mathrm{~mm} / \mathrm{min}$ at $\sim 20^{\circ} \mathrm{C}$.

Axisymmetric pendant drop analysis (KSV instruments CAM101,60 fps digital camera) was used to measure the static surface tension of droplets containing algal exudate. The surface tension of a number of drops, typically $3-5$, with volumes of $\sim 15 \mathrm{~mm}^{3}$ were measured, allowing $50 \mathrm{~min}$ for surface tension equilibration. Samples were prepared by dissolving various masses of desalted dry exudate in deionised water.

\section{Results and discussion}

\subsection{Hygroscopicity of the primary marine aerosol}

Hygroscopic growth in the humidity range from 50 to $93 \%$ $\mathrm{RH}$ was measured for $40,60,80$ and $100 \mathrm{~nm}$ dry diameter $\left(D_{p 0}\right)$ particles produced from different organics-enriched seawater proxies, artificial seawater devoid of marine exudate and natural filtered seawater plus the nutrients medium used for growing the algal cultures. Although the majority of the added nutrients are supposed to be consumed during the algae growth period, the seawater + algal medium measurement was performed in order to compare with the measurements conducted with the samples resulting after algal growth.

Figure 2 shows humidograms (hygroscopic growth factor $\left(\mathrm{GF}_{\mathrm{D} 0, \mathrm{RH}}\right)$, with $\mathrm{D} 0$ indicating the particle size, versus $\mathrm{RH})$ obtained for seawater proxies containing Phaeocystis exudate, along with the theoretical curve for $\mathrm{NaCl}$, which 


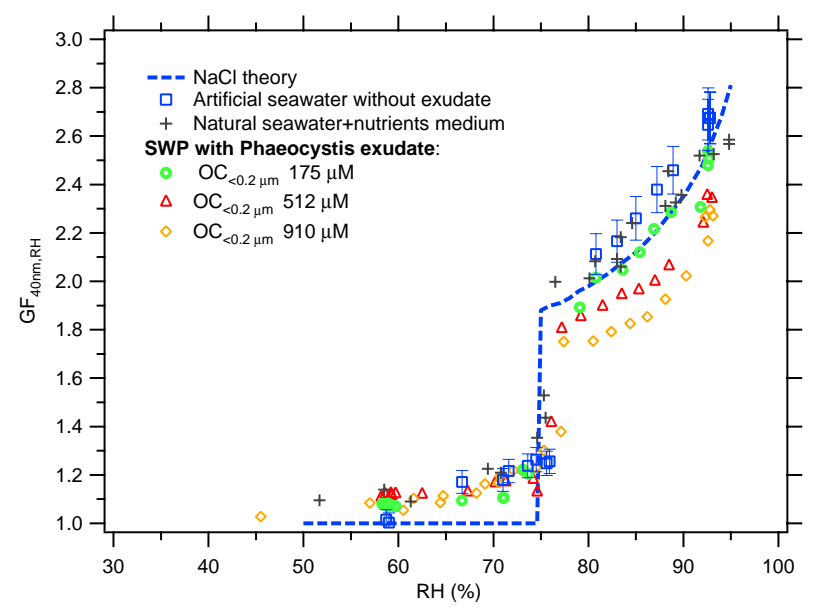

Fig. 2. Humidograms of $40 \mathrm{~nm}$ dry particles $\left(D_{p 0}\right)$ generated by bubble-bursting from artificial seawater and seawater proxies (SWP) containing Phaeocystis exudate, at different organic carbon concentration $\left(\mathrm{OC}_{<0.2 \mu \mathrm{m}}\right)$. A shape factor $\chi=1.04$ was applied to the presented data. Error bars indicate the uncertainty in the diameter selected by the DMA as function of the shape factor correction in the range from spherical $(\chi=1)$ to cubic $(\chi=1.08)$ particles.

was calculated using the detailed thermodynamic model ADDEM (Topping et al., 2005). The error bars indicate the uncertainty associated with the diameter selection by the DMA, calculated considering correction factors in the range from spherical $(\chi=1)$ to cubic shape $(\chi=1.08)$, whereas the presented data corresponds to a shape factor of $\chi=1.04$. Although not included here for clarity of presentation, the same uncertainty range should be considered for all the experiments with seawater.

For the artificial seawater case, observable water uptake already occurred at humidity $>50 \%$, followed by a progressive growth with increasing RH and a substantial water uptake in the 70 to $80 \%$ humidity range, due to the dissolution of the $\mathrm{NaCl}$ crystals. Whilst the hydration behaviour for $\mathrm{RH}$ $<75 \%$ is similar among all the seawater proxy cases studied, above this humidity, the presence of organic material in the sea-salt particles suppresses the growth factor in comparison with the artificial seawater measurements. The magnitude of this suppression, however, is dependent on the concentration of organics in the seawater, with a reduction in the particle growth with increasing seawater organic concentration. A reduction in the growth factor is also observed for the seawater+nutrients case with respect to the artificial seawater measurement. This suppression, attributed to the effect of nutrients and residual marine organic matter in the natural seawater, is less significant than the reduction produced when using seawater proxies with concentrations $>175 \mu \mathrm{M}$ $\mathrm{OC}_{<0.2 \mu \mathrm{m}}$. This indicates that the suppression of the growth above this concentration is certainly due to the organic matter produced by the algal cultures.
Analogous trends in the hygroscopic behaviour were observed in experiments with all other particle sizes and algal exudate tested (Fig. S1 in supplementary material). The reduction in $\mathrm{GF}_{40} \mathrm{~nm}, 90 \% \mathrm{RH}$ for the different cases studied, with respect to production from artificial seawater, ranged from 9$13 \%$ at $175 \mu \mathrm{M} \mathrm{OC}<0.2 \mu \mathrm{m}$ to $10-17 \%$ at $512 \mu \mathrm{M} \mathrm{OC}_{<0.2 \mu \mathrm{m}}$, with dependence on the algal exudate type. The reduction in the growth factor at $90 \% \mathrm{RH}$ in the presented measurements is from the same order to up to $15 \%$ higher than the hygroscopic growth reported in preceding studies on the water uptake of primary marine aerosol $(\leq 10 \%$ for $71-85 \mathrm{~nm}$ dry size) (Sellegri et al., 2008; Modini et al., 2009). No effects on the hygroscopic growth factor, however, were observed for the experiments conducted using the monolayer method. Although this could indicate that the existence of a single monolayer is not sufficient to exert any significant effect on the particle behaviour, it should be noted that the organic layer was not replenished during the duration of the experiments; thus, removal of the monolayer by bubble bursting might have occurred on a timescale shorter than the time required to obtain a measurement. The higher enrichment obtained in the bulk mixing experiments could indicate that the mechanism by which bubbles and particles are substantially enriched in organic matter would be the absorption of organics on the air/water interface of rising bubbles, rather than by the only existence of an organic monolayer on the water surface. The results in this work are however inconclusive, as further work is necessary in order to evaluate the time scale for the removal of organic monolayers by bubble bursting.

Hygroscopic growth probability distributions at $90 \mathrm{RH} \%$ for particles with $\mathrm{D}_{p 0}=40 \mathrm{~nm}$ produced from seawater samples at $512 \mu \mathrm{M} \mathrm{OC}<0.2 \mu \mathrm{m}$ are presented in Fig. 3. The shape of the distributions indicates that the primary marine aerosol generated from seawater enriched with biogenic matter is internally mixed, since a single homogeneous mode was detected. The same behaviour was observed for all the conducted experiments. These results are in agreement with measurements by Sellegri et al. (2008), that showed an internal mixture for 20 and $85 \mathrm{~nm}$ particles generated by bubbling in natural seawater. Marine aerosol particles have been generally found as an internal mixture in clean air masses in the Northern Atlantic Ocean, Southern Atlantic Ocean and Indian Ocean (Swietlicki et al., 2000). Furthermore, an internal mixture between organics and inorganic matter has been found for most of the marine aerosol mass during periods of high biological activity (O'Dowd et al., 2004; Cavalli et al., 2004). The results in Fig. 3 show that the primary marine aerosol is $\sim 20 \%$ more hygroscopic than atmospheric marine aerosol in clean air masses, suggesting the presence of other inorganic salts, like sulphates, and organic components of secondary origin in the atmospheric aerosol. In general, the hygroscopic growth of the aerosol generated from diatomaceous exudate (Chaetoceros and T.rotula) was 5-10\% lower than that of particles generated from nanoplankton exudate 


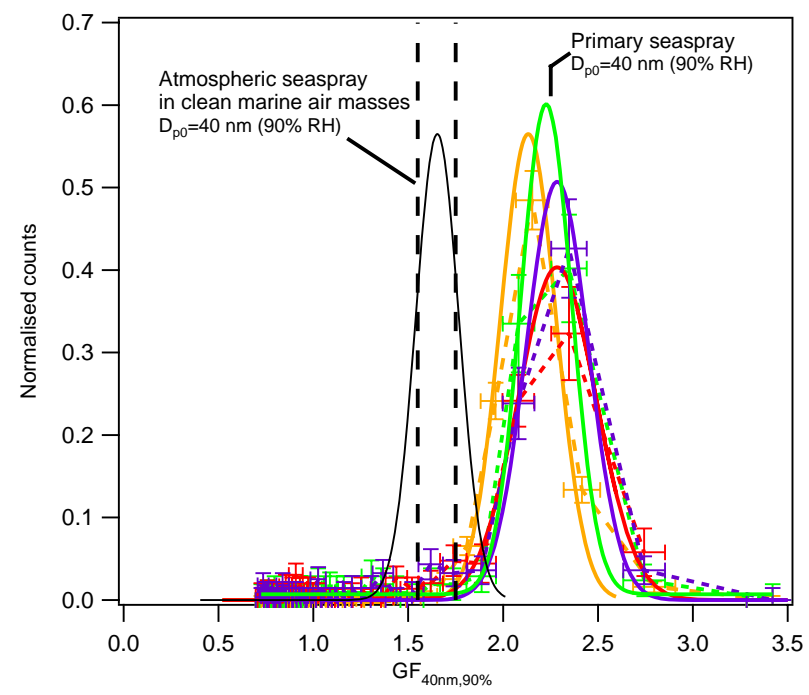

\begin{tabular}{l} 
- Atmospheric seaspray in clean marine air masses \\
(Pacific, Southern oceans and North Atlantic ocean; \\
Swietlicki et al., Tellus, 2000) \\
Primary seaspray from : \\
- SWP with Chaet. exudate \\
- SWP with T. rotula exudate \\
- SWP with Phaeocystis exudate \\
- SWP with E. Huxleyi exudate \\
\hline
\end{tabular}

Fig. 3. Probability distribution of hygroscopic growth factor at $90 \%$ RH for $40 \mathrm{~nm}$ dry particles generated from seawater proxies (SWP) containing different algal organic exudates at $512 \mu \mathrm{M} \mathrm{OC}<0.2 \mu \mathrm{m}$. The atmospheric growth factor distribution in clean air masses is included for comparison. The dashed vertical lines indicate the range of uncertainty for the statistical mode of the atmospheric distribution.

(E. huxleyi and Phaeocystis) (Fig. 3). In an analogous manner, in the experiments with algal mixtures the highest suppression occurred for the mixtures with the greatest proportion of diatomaceous exudate (Chaetmix and TRotulamix samples).

\subsection{Organic enrichment of the primary marine aerosol}

The Zdanovskii-Stokes-Robinson mixing rule (ZSR) (Stokes and Robinson, 1966) can be used as a simplified approach to estimate the composition of the primary particles using the hygroscopicity measurements. In the above experiments it was shown that the hygroscopicity of seawater devoid of exudate is similar to the growth of pure $\mathrm{NaCl}$ particles after deliquescence. Adopting the simplification that the postdeliquescence growth of the inorganic fraction in the primary marine aerosol can be approximated to the growth of pure $\mathrm{NaCl}$, the ZSR rule was applied to calculate the hygroscopic growth factor of a mixed primary marine particle as:

$\mathrm{GF}_{\text {particle }}=\left(\left(1-\varepsilon_{\text {org }}\right) \mathrm{GF}_{\text {inorg }}^{3}+\varepsilon_{\text {org }} \mathrm{GF}_{\text {org }}^{3}\right)^{1 / 3}$

where $\varepsilon_{\text {org }}$ is the organic volume fraction in the dry particle and $\mathrm{GF}_{\text {inorg }}$ and $\mathrm{GF}_{\text {org }}$ are the pure inorganic and organic growth factors, respectively. The use of the ZSR implies the assumption that the organic and inorganic fractions absorb water independently. Investigation on the water uptake of mixed particles made up of $\mathrm{NaCl}$ and organic solutes has suggested the existence of a negative interaction between the organic and inorganic fractions during hygroscopic growth (Cruz and Pandis, 2000). Predictions of growth factors based on the assumption of independent water absorption, however, have been shown to agree with measurements within $20 \%$ (Cruz and Pandis, 2000), thus, this approach is applied in this study as a good first-order estimation of the composition of the particles.

Equation (1) was applied at 90\% RH considering the growth factor of pure $\mathrm{NaCl}$ for the particle inorganic fraction as derived from the ADDEM model $\left(\mathrm{GF}_{\text {inorg }}=2.35\right)$ (Topping et al., 2005) and a hygroscopic factor for the organic fraction of 1.1, representative of oxidised organic aerosols (McFiggans et al., 2005). Predictions using the ZSR approximation at $90 \% \mathrm{RH}$ with an organics growth factor of 1.1 yielded particle organic volume fractions from 8 to $37 \%$ for seawater organic concentration $\mathrm{OC}_{<0.2 \mu \mathrm{m}}$ between 175 and $512 \mu \mathrm{M}$.

The sensitivity of the predicted composition to the assumption of $\mathrm{GF}_{\text {org }}$ is relatively small, since within the relevant range of growth factors for compounds representative of marine organics $\left(\mathrm{GF}_{\text {org }}=1-1.5\right.$ at $90 \% \mathrm{RH}$, (Peng et al., 2001; Mikhailov et al., 2004; Gysel et al., 2004)), the maximum difference of the predicted organic fraction is 0.05 . It should be remarked that this sensitivity analysis is valid only for the order of organic fraction concentrations found in this study. The derived mean organic fraction for the diatomaceous exudate (Chaetoceros and T. rotula) is 5-10\% larger than the volume fraction for the nanoplankton exudate, with a difference $>0.05$ at any organic growth factor $\mathrm{GF}_{\text {org }}$ between $1-1.5$. Hence, it can be concluded that the organic fraction of the particles produced from diatomaceous exudate is higher than for the other cases studied, beyond the uncertainty in the assumption of $\mathrm{GF}_{\text {org. }}$. In addition, the mean difference between the Chaetoceros and $T$. rotula organic fractions is larger than the uncertainty value, with Chaetoceros presenting a higher organic fraction than $T$. rotula. However, the difference between the organic fractions within the nanoplankton group (E. Huxleyi and Phaeocystis) is within uncertainty limits, thus, it is not possible to determine whether the particles generated from these two types of exudate present a different organic enrichment.

Analysis of the relationship between the particle organic volume fraction and the organic carbon content of the seawater employed for aerosol production (Fig. 4) indicates that the particle organic fraction is proportional to the organic matter concentration in the seawater proxy. The equilibrium adsorption of organics by rising bubbles increases with increasing organic concentration in the liquid media (Fuentes et al., 2010a), which explains the correlation between the seawater and the particle organic enrichment. 
The derived organic volume fractions were converted into organic mass fractions in order to compare with measurements of atmospheric marine aerosol organic enrichment by O'Dowd et al. (2008) and their revised version (Vignati et al., 2010). For the conversion a density of $1400 \mathrm{~kg} / \mathrm{m}^{3}$, representative of oxidised organic aerosols, was applied for the organic fraction (Alfarra et al., 2006; Dinar et al., 2006). Since this density is in the upper range of density values for organic compounds, the derived composition constitutes an upper limit estimation of the organic mass fraction in the marine particles. For a direct comparison of our results with the atmospheric measurements, the seawater organic carbon concentration was converted to the corresponding Chl-a concentration using the mass balance equation presented in Fuentes et al. (2010b). This balance provides a first-order estimation of the relationship between the Chl-a biomass in an algal bloom and the corresponding production of labile and semilabile organic carbon, using parameters such as the $\mathrm{C}$ :Chl-a ratio and the lifespan of the algal cells.

Figure 5 shows the data from the present study in comparison with the atmospheric aerosol organic fraction determined by O'Dowd et al. (2008), as a function of the seawater Chl-a concentration. The solid red line represents the average curve through the primary aerosol data, while the dashed red lines indicate the uncertainty in determining the relationship between the organic matter in the seawater and the Chl-a biomass concentration. The uncertainty range in the relationship between the seawater primary organic carbon and Chl-a biomass presented in Fig. 5 is due to the fact that the organic production by marine biota is formulated not only as a function of the Chl-a concentration, but also dependent on the specific conditions in the algal blooms, like nutrients availability, temperature (affecting Chl-a:C mass ratio) and lifespan of algal cells (Fuentes et al., 2010b). Since the particle organic fraction is a function of the seawater organic matter content (Fig. 4) and the organic matter production in algal blooms is not exclusively dependent on the seawater Chl-a concentration (Fuentes et al., 2010b), it is likely that regional relationships between particle organic mass fraction and Chl-a (O'Dowd et al., 2008; Vignati et al., 2010) might not be applicable on a global scale. The uncertainty curves for the primary marine aerosol indicate that higher particle organic fractions are expected in algal blooms regions with high C:Chl-ratio and low grazing, since these conditions favour the production of organic matter at lower Chl-a concentrations. Most of the primary aerosol data lay on the Chl-a region between $0.4-10 \mu \mathrm{g} / \mathrm{L}$, which is representative of areas with high biological activity. The range of high Chl-a values for the primary aerosol dataset is consistent with the high organic concentration in the seawater proxies employed in the presented experiments (most of the samples were enriched with $\left.\mathrm{OC}_{<0.2 \mu \mathrm{m}}>175 \mu \mathrm{M}\right)$, considering that the average concentration of organic carbon in the oceans, including the refractory organic pool, is $50-80 \mu \mathrm{M}$ (Owaga and Tanque, 2003),
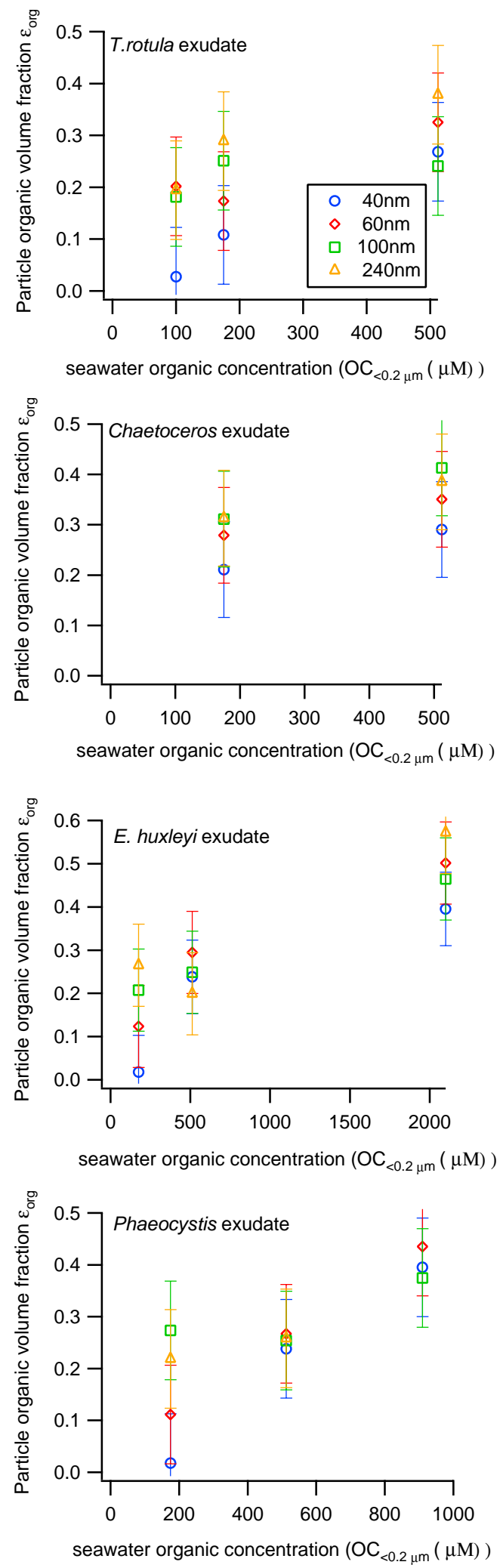

Fig. 4. Particle organic volume fraction versus seawater organic concentration for different algal exudates and particle sizes calculated using the $\mathrm{ZSR}$ rule with $\mathrm{GF}_{\text {org }}=1.1$. 


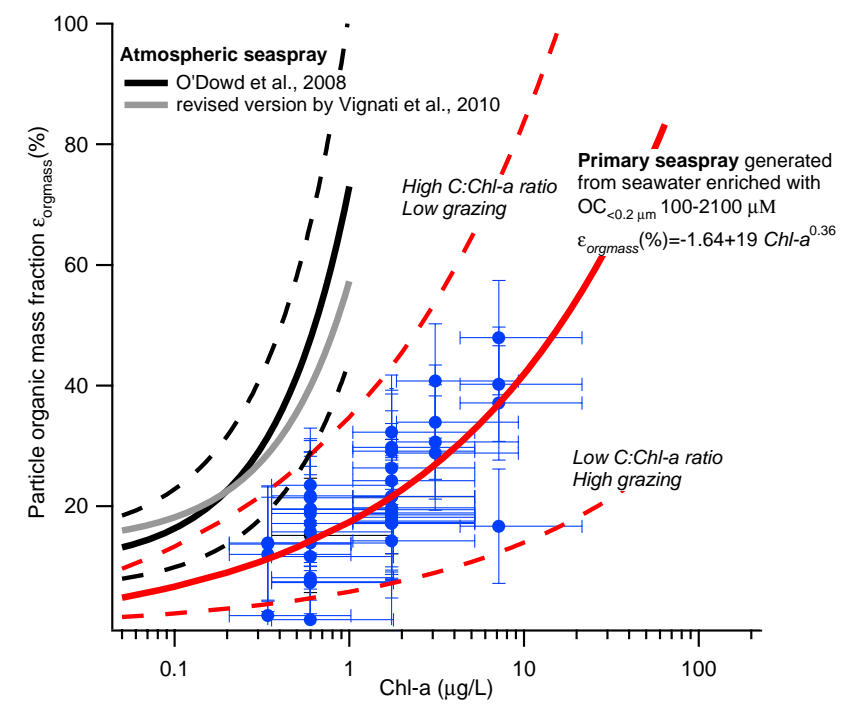

Fig. 5. Comparison of organic mass fractions in atmospheric marine aerosol (O'Dowd et al., 2008; Vignati et al., 2010) (solid black line: average; dashed black lines: uncertainty range) and upper estimate of organic mass fraction in the primary marine aerosol (symbols: experimental data; solid red line: average curve through the data; dashed red lines: uncertainty range). The uncertainty range for the atmospheric marine aerosol indicates $100 \%$ data confidence limits and the uncertainty curves and error bars for the primary aerosol data represent the uncertainty in determining the relationship between the organic matter in seawater and Chl-a biomass (Fuentes et al., 2010b).

and that the Chl-a concentration in low biologically activity areas is frequently below $0.4 \mu \mathrm{g} / \mathrm{L}$ (Perez et al., 2001). It is remarkable that saturation of the organic mass fraction of the primary aerosol does not occur even for unrealistically high $\mathrm{OC}_{<0.2 \mu \mathrm{m}}$ concentrations $\geq 910 \mu \mathrm{M}$.

For Chl-a concentration $<0.5 \mu \mathrm{g} / \mathrm{L}$ (particle organic mass fraction below 30\%) the primary and atmospheric marine aerosol uncertainty regions partially overlap, thus indicating that the primary organics could constitute from $50 \%$ to $100 \%$ of the organic fraction in the atmospheric particles in this range. However, for higher Chl-a concentrations (i.e. higher organic matter concentration in the seawater) the organic fraction in the primary aerosol is lower than the organic fraction in the atmospheric particles. It is remarkable that even for very high organic concentrations in seawater (e.g. $\mathrm{OC}_{<0.2 \mu \mathrm{m}} 2100 \mu \mathrm{M}$ ), the organic mass fraction of the primary aerosol is not higher than $58 \%$, while the atmospheric measurements already exhibit an averaged organic fraction of $\sim 80 \%$ at a Chl-a concentration of $\sim 1 \mu \mathrm{g} / \mathrm{L}$. The present work, together with previous studies on the hygroscopicity of the primary marine aerosol (Sellegri et al. (2008) with North Atlantic waters and Modini et al. (2009) with coastal waters (the latter possibly affected by river run-off)) yield particle organic volume fractions considerably lower than the organic mass fractions reported by Facchini et al. (2008) and

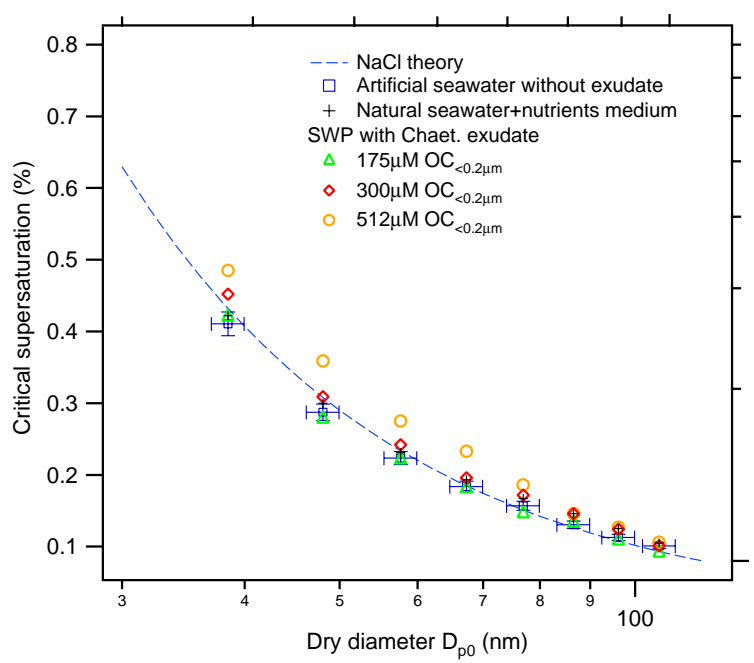

Fig. 6. Critical supersaturation as a function of particle diameter for the aerosol generated from artificial seawater and seawater proxies (SWP) enriched with Chaetoceros exudate at different organic concentrations. A shape factor $\chi=1.04$ was applied to the presented data. Horizontal error bars indicate the uncertainty in the diameter selected by the DMA as function of the shape factor correction in the range from spherical $(\chi=1)$ to cubic $(\chi=1.08)$ shape. Vertical bars indicate the mean uncertainty in the determination of the critical supersaturation taken as $\pm 1 \sigma$ standard deviation.

O'Dowd et al. (2008). Although the discrepancy between the present study and results in Facchini et al. (2008) and O'Dowd et al. (2008) could be thought to be due to the fact that the samples in the present study were filtered for $\mathrm{OC}_{<0.2 \mu \mathrm{m}}$, this argument is not definitive, since similar hygroscopic growth suppression to our study was observed by Sellegri et al. (2008) in experiments with natural unfiltered seawater.

It is remarkable that differences between the primary and atmospheric aerosol compositions could also be attributed to the existence of secondary organic matter in the atmospheric aerosol. The correlation between Chl-a and particle organic fraction in the measurements of O'Dowd et al. (2008) is low $\left(r^{2}=0.25\right)$, indicating that part of the variance in the dataset is possibly due to secondary processing incorporating organics that may or may not be of marine origin. This would be the case of formation of secondary organic aerosol from non-methane hydrocarbon and glyoxal emissions derived from the algal photosynthetic activity (Meskhidze and Nenes, 2006; Shapiro et al., 2009). The results presented in this section have shown that the particle organic enrichment depends on the seawater organic concentration and type of organic exudate. Thereby, discrepancies between different laboratory studies on the composition of the primary aerosol could partly be attributed to the different organic content in the source seawater employed. The concentration of colloidal matter $\mathrm{OC}_{<0.2 \mu \mathrm{m}}$ in surface waters has been found to vary by a factor of up to 4.5 , depending on the location 
(Wells and Goldberg, 1993), thus it is expected to find diverging organic enrichment in particles generated from different source seawater.

\subsection{CCN activity of primary marine aerosol}

The CCN activity of particles generated from artificial seawater and seawater proxies containing biogenic organics was characterised for dry particle diameters between 40 and $110 \mathrm{~nm}$. Critical supersaturations obtained for seawater enriched with Chaetoceros exudate are shown in Fig. 6, along with the theoretical curve for $\mathrm{NaCl}$ and the results for the experiment with natural seawater plus the nutrients medium. The horizontal error bars account for the uncertainty in the selection of the particle diameter by the DMA in the range from spherical $(\chi=1)$ to cubic $(\chi=1.08)$ particle shape, and the vertical error bars indicate the uncertainty in the determination of the critical supersaturation taken as $\pm 1 \sigma$ standard deviation. Although not included in all the cases in the plots in Fig. 6 for clarity of presentation, the same uncertainty range should be considered in all the experiments.

Whereas the measurements with artificial seawater without organics and the seawater+nutrients medium indicate that the particles produced from these samples presented a behaviour similar to pure $\mathrm{NaCl}$, the presence of biogenic organics in seawater caused an increase in the critical supersaturation in the range $5-24 \%$ with respect to the case without algal exudate. In a similar way to the hygroscopic growth analysis, the observed effect is observed to be positively correlated with organic concentration in the seawater. This effect was observed for all the algal exudates studied (Fig. S2).

Furthermore, the CCN aerosol activity was found to depend on the type of algal exudate in the seawater proxy. Figure 7 shows the measurements for seawater samples containing one type of exudate at identical concentration $(512 \mu \mathrm{M}$ $\mathrm{OC}_{<0.2 \mu \mathrm{m}}$ ). Figure 7 (B) indicates the relative variation of the critical supersaturation with respect to the case of artificial seawater without exudate. The experiments with diatomaceous exudate show a stronger effect on the critical supersaturation than the experiments with nanoplackton exudate, with the greatest effect observed for the Chaetoceros seawater proxy. Regarding the experiments with exudate mixtures, in like manner to the hygroscopicity measurements, the effect of the Chaetmix exudate was the largest in comparison with the rest of the samples (Fig. S3), which is in agreement with the observations for the single exudates.

\subsection{Molar mass of algal exudates}

Compression isotherms (surface pressure versus film area) of algal exudate monolayers, obtained from measurements with a Langmuir trough, were used to derive the molar mass of the hydrophobic fraction of the marine organics in the seawater sample remaining after filtration at $0.2 \mu \mathrm{m}$. To apply this approach, the isotherms of marine surfactants were de-
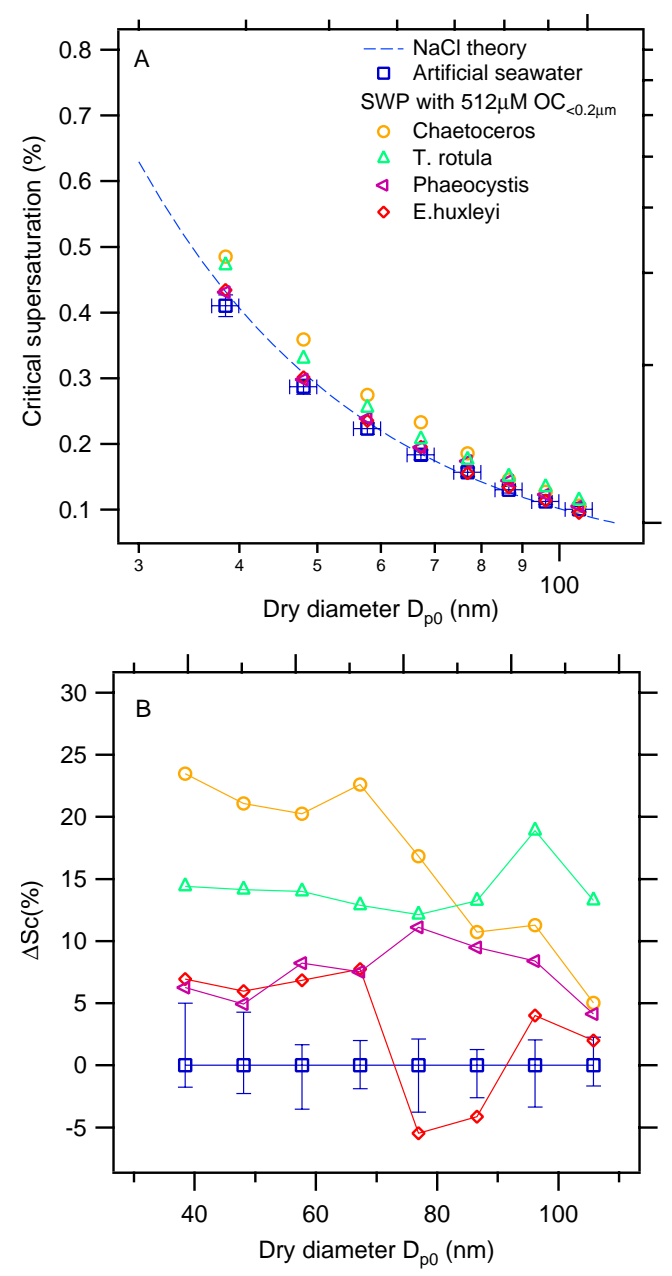

Fig. 7. (A) Critical supersaturation as a function of particle diameter for the aerosol generated from artificial seawater and seawater proxies (SWP) enriched with algal exudate at $512 \mu \mathrm{M} \mathrm{OC}<0.2 \mu \mathrm{m}$ and $(B)$ relative variation in the critical supersaturation $\mathrm{Sc}$ with respect to the critical supersaturation for the case without exudate.

fined in the form of a two-dimensional virial equation of state as (Pogorzelski and Kogut, 2003; Barger and Means, 1985) :

$\pi A=C_{0}+C_{1} \pi+C_{2} \pi^{2}$

where $\pi$ is the surface pressure, defined as the surface tension reduction with respect to the surface tension of pure water, $\mathrm{A}$ is the film area and $\mathrm{C}_{0}, \mathrm{C}_{1}$ and $\mathrm{C}_{2}$ are the virial coefficients.

The number of molecules in the film, the limiting area and the molar mass of the different exudate films can be obtained from the virial coefficients in Eq. (2) (Pogorzelski and Kogut, 2003). The number of molecules $n_{m}$ in the film and the limiting specific area are defined as (Pogorzelski and Kogut, 2003):

$n_{m}=2 C_{0} / k T$

$A_{\lim }=C_{1} N_{A} / n_{m} \times 10^{14}$ 


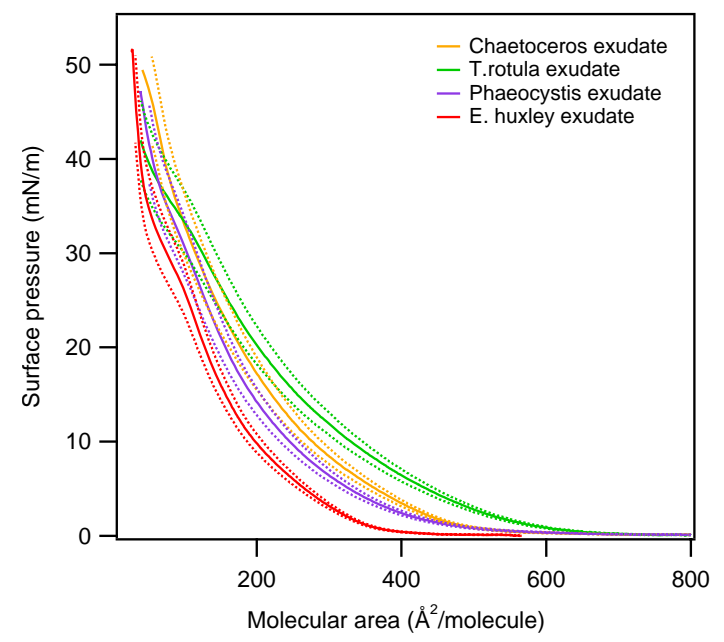

Fig. 8. Surface pressure-area isotherm of films of marine organics released by different algal cultures at $20^{\circ} \mathrm{C}$ as determined from Langmuir trough compression measurements. The dashed lines indicate the uncertainty limits.

where $k$ is the Boltzmann constant, $T$ the temperature and $N_{A}$ the Avogadro number.

Following the approach of Pogorzelski and Kogut (2003), the algal exudate molar mass is calculated under the assumption that the mean mass of a film of marine organics required to produce a surface tension reduction of $\pi=$ $20 \mathrm{mN} / \mathrm{m}$ at $119.54 \mathrm{~cm}^{2}$ is approximately $24 \mu \mathrm{g}$. This assumption is based on experiments with 16 model surfaceactive substances present in seawater, which yielded a mean film mass of $24 \pm 6.2 \mu \mathrm{g}$ (Barger and Means, 1985). Thereby, the molar mass $\left(\mathrm{M}_{\mathrm{org}}\right)$ is calculated as:

$M_{\mathrm{org}}=24 \times\left(A_{\pi=20} / 119.54\right) / n_{m}$

where $A_{\pi=20}$ is the film area for $\pi=20 \mathrm{mN} / \mathrm{m}$.

Figure 8 shows the $\pi$-A isotherms for films of the different algal exudates used in this study as obtained from the conducted measurements. The resulting isotherms are typical of surfactants forming expanded films, characterised by a monotonic increase of the surface pressure with the surface film reduction and the appearance of kinks reflecting phase transitions of higher orders. Isotherms with similar characteristics to these have been observed in analogous experiments with marine surfactant films (Pogorzelski and Kogut, 2003).

Table 3 includes the values of the virial coefficients, limiting area and molar mass derived from the isotherms in Fig. 8. Least square fitting of the experimental data to the virial equation of state yielded coefficient regressions $>0.87$ $(P<0.01)$. The molar mass and limiting area of marine organic films are typically in the range of $0.65-9.71 \mathrm{kDa}$ and 268-3157 A 2 /molec, respectively (Pogorzelski and Kogut, 2003). The values derived in this work are closer to the lower

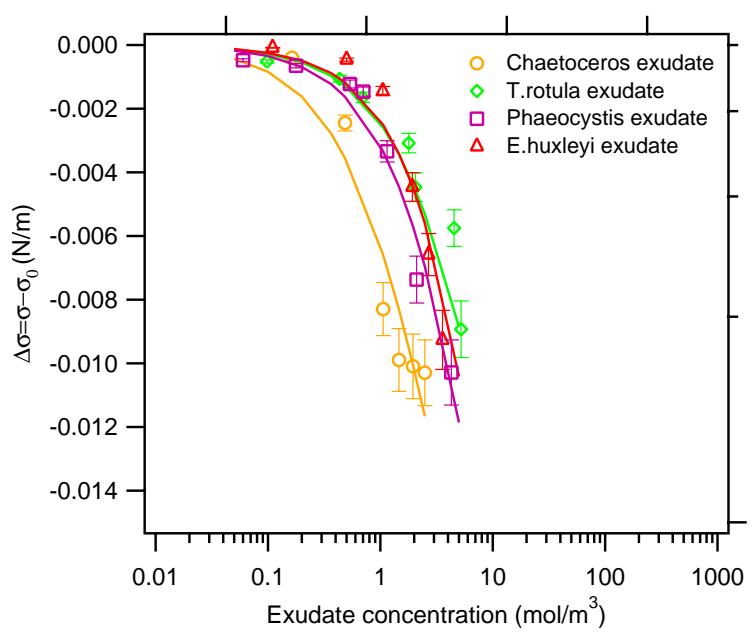

Fig. 9. Szyskowski-Langmuir surface tension isotherms for the algal exudates on study as determined from axisymmetric pendant drop analysis at $20^{\circ} \mathrm{C}$. Vertical bars indicate the mean uncertainty in the determination of the surface tension taken as $\pm 1 \sigma$ standard deviation.

end of these ranges, which has been associated to surface films collected in areas away from the influence of anthropogenic emissions (Pogorzelski and Kogut, 2003), although this could also be due to the fact that the extracted hydrophobic material contains only organic matter $<0.2 \mu \mathrm{m}$. The high values of molar mass found $(1.37-2.37 \mathrm{kDa})$, however, provide experimental evidence of the existence of truly colloidal substance in the organic pool $<0.2 \mu \mathrm{m}$ isolated from the seawater samples. These values are also consistent with the molar mass of the colloidal nanogels size range reported in the literature (Verdugo et al., 2004).

\subsection{Application of Köhler theory}

Surface tension measurements, using the pendant drop technique, were performed in order to determine the surface tension isotherms for each of the algal exudates on study. From these measurements, the surface tension can be defined as a function of the droplet exudate concentration following the Szyskowski-Langmuir adsorption isotherm Langmuir (1917) as:

$\sigma=\sigma_{\mathrm{w}}-R T \Gamma_{\infty}\left[\ln \left(1+1 / a_{L} C_{\mathrm{org}}\right)\right]$

where $\sigma_{\mathrm{w}}$ is the surface tension of water, $C_{\mathrm{org}}$ is the organic concentration in the droplet, $a_{\mathrm{L}}$ is the Langmuir parameter (concentration at half surface coverage, $\mathrm{mol} / \mathrm{m}^{3}$ ) and $\Gamma_{\infty}$ is the saturation surface excess $\left(\mathrm{mol} / \mathrm{m}^{2}\right)$. The isotherms obtained for the different algal exudate samples are illustrated in Fig. 9, while the values of $a_{\mathrm{L}}$ and $\Gamma_{\infty}$ are listed in Table 3.

In order to evaluate the $\mathrm{CCN}$ behaviour of the primary sea spray the Köhler model was used with input of the surface tension and composition of the primary particles. The Köhler 
Table 3. Virial coefficients of the two-dimensional equation of state defining the compression isotherms of the marine exudate films, limiting area, inferred molar masses and parameters of the Szyskowski-Langmuir adsorption isotherms.

\begin{tabular}{lccccccc}
\hline Exudate film & $\mathrm{C}_{0}(\mathrm{erg})$ & $\mathrm{C}_{1}\left(\mathrm{~cm}^{2}\right)$ & $\mathrm{C}_{2}\left(\mathrm{~cm}^{2} \mathrm{dyn}\right)$ & $A_{\text {lim }}\left(A^{2} / \mathrm{molec}.\right)$ & $M_{\mathrm{w}}(\mathrm{kDa})$ & $a_{\mathrm{L}}\left(\mathrm{mol} / \mathrm{m}^{3}\right)$ & $\Gamma_{\infty}\left(\mathrm{mol} / \mathrm{m}^{2}\right)$ \\
\hline T. rotula & 59.3 & 93.8 & -2.1 & 322.4 & $2.37 \pm 0.20$ & 2.37 & $4.2098 \mathrm{e}-006$ \\
Chaetoceros & 55.5 & 75.3 & -1.4 & 276.5 & $2.22 \pm 0.22$ & 1.17 & $4.1337 \mathrm{e}-006$ \\
E. huxleyi & 87.2 & 73.3 & -1.5 & 171.2 & $1.37 \pm 0.14$ & 12.8 & $1.2746 \mathrm{e}-005$ \\
Phaeocystis & 59.1 & 74.8 & -1.5 & 257.7 & $1.99 \pm 0.20$ & 4.54 & $6.4815 \mathrm{e}-006$ \\
\hline
\end{tabular}

theory defines the saturation ratio, $S$, over an aqueous solution droplet, as a function of the water activity $a_{\mathrm{w}}$ in both sub- and supersaturated regimes as:

$S=a_{\mathrm{w}} \exp \left(\frac{4 \sigma_{\mathrm{s}} M_{\mathrm{w}}}{\rho_{\mathrm{w}} R T D}\right)$

where $\sigma_{s}$ is the droplet surface tension, $M_{\mathrm{w}}$ is the molecular weight of water, $\rho_{\mathrm{w}}$ is the density of water, $R$ is the universal gas constant, $T$ is the absolute temperature and $D$ is the droplet diameter.

The term defined by the water activity is the Raoult term, while the exponential part of the equation is the Kelvin term. In the same manner as in the previous section, the $\mathrm{CCN}$ activity of the inorganic solute is approximated to the $\mathrm{CCN}$ behaviour of pure $\mathrm{NaCl}$. The assumption that the organic solute in the particle is fully dissolved may not be representative for aqueous solutions of marine organic exudate, since most of the organic carbon in the submicron primary marine aerosol has been found to be comprised by water insoluble organic carbon (WIOC) (Facchini et al., 2008).

In order to consider the degree of solubility of the organic fraction, the Raoult law for a mixture of $\mathrm{NaCl}$ and an organic solute is defined as (Raymond and Pandis , 2003):

$a_{\mathrm{w}}=\gamma_{\mathrm{w}} \frac{n_{\mathrm{w}}}{n_{\mathrm{w}}+\phi_{\mathrm{NaCl}} v_{\mathrm{NaCl}} n_{\mathrm{NaCl}}+\xi_{\text {org }} \phi_{\text {org }} v_{\text {org }} n_{\text {org }}}$

where $\gamma_{\mathrm{w}}$ is the water activity coefficient of the solution, $n_{\mathrm{NaCl}}, \phi_{\mathrm{NaCl}}$ and $v_{\mathrm{NaCl}}, n_{\mathrm{org}}, \phi_{\text {org }}$ and $v_{\text {org }}$ are the total number of moles, osmotic coefficient and number of ions per solute, for the inorganic and the organic compound, respectively, $\xi_{\text {org }}$ refers to the dissolved mass fraction of the organic solute and $n_{w}$ is the number of water molecules in the droplet. For the case of complete dissolution the factor $\xi_{\text {org }}$ is equal to unity while for limited solubility this factor is less than unity. The expression in Eq. (8) is a modified version of the Köhler model which allows its use for substances with limited solubility (Raymond and Pandis , 2003). The application of this modified version of the Köhler model to organic compounds of limited solubility with small contact angle, i.e., to highly wettable compounds, leads to significant deviations between experiments and theory (Raymond and Pandis , 2003). For these type of species reasonable predictions are obtained under the assumption that compounds of limited solubility which are highly wettable behave as if they were completely soluble (Raymond and Pandis , 2003).

The value of water uptake under a fully soluble assumption for polymeric compounds might not be well represented by Raoult's law, due to the large difference in size between the organic polymer and the solvent (Petters et al., 2006). Because of the large difference between the molar volumes of solvent and solute, the water vapour pressure over the solution is suppressed relative to Raoult's law and a higher water content would be required to establish equilibrium at a given humidity. The Flory-Huggins theory is preferably applied to describe the water activity in a binary water-polymeric matter solution as:

$\ln a_{\mathrm{w}}=\ln (1-\phi)+\left(1-\frac{1}{f}\right) \phi+\chi \phi^{2}$

where $\phi$ is the polymeric matter volume fraction, $f$ is the chain segment number, calculated as the ratio of the molecular volumes of the polymer and solvent, and $\chi$ is the FloryHuggins interaction parameter, which depends on the polymer volume fraction. The values of $\chi$ were estimated from the parameterisation derived by Petters et al. (2006) using experimental data for PAA (polycarboxilic acid) and the approach of Wolf (2003). In the approach of Petters et al. (2006), the Flory-Huggins interaction parameter was derived from hygroscopicity experimental data for pure organic particles, with extrapolation to diluted conditions for its application in cloud activation predictions. PAA is a polycarboxilic acid with a molar mass of $2 \mathrm{kDa}$ and a hygroscopic growth of 1.15-1.18 at 90\%RH (Petters et al., 2006). As the molar mass of PAA is on the order of organic matter present in the marine exudate (this work and (Pogorzelski and Kogut, 2003)) and polycarboxilic acids are components released by phytoplankton excretion (Bertilsson et al., 2005) it will be assumed that the interaction parameter derived for PAA by Petters et al. (2006) is a valid approximation for application to marine biopolymer.

The Flory-Huggins theory was originally formulated for binary polymer-water solutions with homogeneous segment density (Fried, 2003), i.e. for concentrated polymer solutions. The Flory-Krigbaum theory is a modification of the Flory-Huggins approach to predict the behaviour of polymers in diluted solutions, where individual polymer chains are isolated and surrounded by regions of solvent and 
segmental density is not considered uniform (Fried, 2003). It should be evaluated whether the extrapolation of FloryHuggins interaction parameter calculation to the diluted conditions characterising cloud activation is valid to predict the behaviour of the organic particles, in comparison with predictions by Flory-Krigbaum theory. Because of the measurement uncertainty in the hygroscopicity measurements with mixed primary marine particles in the present study, it is not possible to accurately determine the water content bound to the organic fraction and test these formulations. Further research with pure organic particles should be conducted in order to asses the validity of Flory-Huggins and FloryKrigbaum for predicting the solution behaviour and cloud activation of marine biopolymers.

Equations (6) to (9) were applied to model the activation behaviour of pure organic particles and mixed particles generated from seawater at $512 \mu \mathrm{M} \mathrm{OC}<0.2 \mu \mathrm{M}$ using the compositions derived from the ZSR approach. Flory-Huggins theory and Raoult's law were applied in the modelling of water activity in order to compare the predictions obtained with this two approaches. For the mixed particles, the cases of full solubility $\left(\xi_{\text {org }}=1\right)$, and effective insolubility $\left(\xi_{\text {org }}=0\right)$ were evaluated. The case of effective insolubility represents an undissolved organic matter core that does not dissolve with increasing droplet size, thus, does not contribute to a reduction of the surface tension in the droplet. The case of sparingly soluble compounds $\left(\xi_{\text {org }}<1\right)$ falls between these two cases.

For the determination of the concentration of organics in the droplet, partitioning of the organics between the bulk and the surface was estimated by applying the Gibbs surface thermodynamics approach defined by Sorjamaa et al. (2004), using the methodology described in Wex et al. (2008). Partitioning was found to be negligible for the organic compounds studied. The low value of the organic concentration at half surface coverage $a_{\mathrm{L}}\left(a_{\mathrm{L}}=1.17-12.8 \mathrm{~mol} / \mathrm{m}^{3}\right.$, equivalent to $B=0.08-0.85 \mathrm{~m}^{3} / \mathrm{mol}$, according to Sorjamaa et al. (2004)) defining the surface tension isotherms indicates that the marine organics $<0.2 \mu \mathrm{m}$ exhibit moderate surface active properties and that partitioning is negligible for these organic compounds (Sorjamaa et al., 2004).

Since activation occurs at diluted conditions, a water activity and osmotic coefficients of unity were employed. An average density of $1400 \mathrm{~kg} / \mathrm{m}^{3}$ for the organic compounds was used in the calculations. The predictions presented a low sensitivity to the assumption of the organics density, with a variation $<2 \%$ for the predicted values in the range of densities from 1000 to $1400 \mathrm{~kg} / \mathrm{m}^{3}$. The results also exhibit a relatively low sensitivity to the assumption of the organics growth factor applied to derive the particle composition with the ZSR rule, with variations $<5.5 \%$ in the predicted critical supersaturation in the range of organics growth factor between 1 and 1.5.

Predictions using Flory-Huggins' theory for the purely organic particles yielded critical supersaturation values lower
Table 4. Theoretical prediction of $\kappa$-Köhler values for pure marine exudate particles derived using Köhler theory in combination with Flory-Huggins and Raoult's law. The $\kappa$-Köhler values derived using Flory-Huggins are $1.2-17 \%$ higher than those obtained using Raoult's law, with larger differences between the predictions for increasing chain segment number.

\begin{tabular}{lccc}
\hline & $\kappa$-Flory-Huggins & $\kappa$-Raoult & $\begin{array}{c}\text { chain segment } \\
\text { number } \mathrm{f}\end{array}$ \\
\hline T. rotula & 0.073 & 0.062 & 94 \\
Chaetoceros & 0.111 & 0.105 & 88 \\
E.huxleyi & 0.164 & 0.162 & 56 \\
Phaeocystis & 0.118 & 0.113 & 79 \\
\hline
\end{tabular}

than those obtained using Raoult's law. Table 4 includes the values of $\kappa$-Köhler derived from the critical supersaturation curves for the four exudates on study (method of calculation described in Sect. 4). Because of the higher water absorption obtained with Flory-Huggins, the resulting $\kappa$-Köhler values are 1-18\% higher in the modelling with Flory-Huggins with respect Raoult's law calculations.

Figure 10 shows the results of the Köhler model obtained for primary marine particles generated from the seawater proxy containing $512 \mu \mathrm{M} \mathrm{OC}<0.2 \mu \mathrm{m}$ Chaetoceros exudate. The differences between the predictions using Raoult's law and Flory-Huggins for the mixed particles are lower than $0.5 \%$, thus only the curves from the Raoult's law calculations have been represented in this figure. In agreement with the experiments, the Köhler model predicts an increase in the critical supersaturation upon the replacement of the inorganic salt by organic solute, due to the fact that the surface tension effect in the Kelvin term is dominated by the reduction in the number of solute molecules in the Raoult term. Model calculations for the other algal exudates are included in Fig. S4 in the supplementary material. The results indicate a reasonable agreement between the experiments and theoretical results for the full solubility case, with mean deviations between experiments and model $<5 \%$ for the T.rotula and Chaetoceros cases and $<10 \%$ for the nanoplankton exudate (E.huxleyi and Phaeocystis).

Most of the dry particle composition is made up of seasalt, implying that most of the water uptake is induced by the inorganic fraction of the particle. Hence, although the behaviour of pure exudate particles might be better represented by the Flory-Huggins equation, the Raoult's law constitutes a valid approximation to predict the cloud condensation activity of mixed primary marine particles enriched with $\mathrm{OC}<0.2 \mu \mathrm{m}$. In addition, the reasonable agreement between experiments and model indicates that the composition derived using the ZSR approach is adequate as an estimation of the composition of the particles.

The theoretical calculations indicated a reduction of the surface tension at the point of activation from $5 \%$ to $1.8 \%$ 


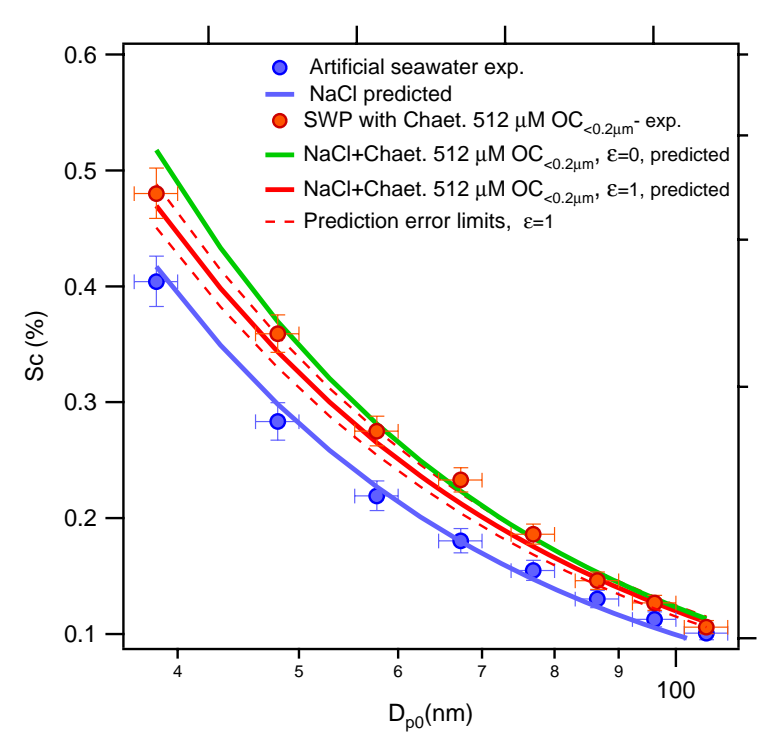

Fig. 10. Experimental and predicted critical supersaturation as a function of the dry particle size for primary marine aerosol generated from artificial seawater devoid of organics and seawater proxy containing Chaetoceros exudate, at $512 \mu \mathrm{M} \mathrm{OC}<0.2 \mu \mathrm{m}$. No visual differences are appreciated between Flory-Huggins and Raoult's law predictions with deviations $<0.5 \%$. The particle composition employed was derived from hygroscopicity data by applying the ZSR approximation.

for particles generated from Chaetoceros exudate, 1.9-0.5\% reduction for T.rotula and less than $0.5 \%$ for the nanoplankton exudate particles. The discrepancy between the cases of full solubility and effective insolubility for the particles generated from Chaetoceros exudate is due to the suppression of the surface tension occurring in the case of full solubility, which leads to an increase in the $\mathrm{CCN}$ activity with respect to the effective insolubility case. On the other hand, lower discrepancy between the two solubility cases was found for the particles generated from the rest of the exudates, due to the lower surface tension suppression occurring at activation for these particles. Assuming that the majority of the marine organics are water insoluble (Facchini et al., 2008), the agreement between the case of full solubility and the experiments for the Chaetoceros experiments indicates that marine organics are highly wettable compounds (Raymond and Pandis , 2003). It is remarkable that, in similar manner to the presented analysis, modelling of the CCN activity of mixed particles made of ammonium sulphate and aminoacids of low solubility, has shown that most of these compounds activate as though they were fully soluble, implying curvatureenhanced solubility (Kristensson, 2010).

It has been postulated that the presence of primary organic matter in the marine aerosol can enhance the cloud condensation activity through the suppression of the surface tension in the Kelvin term of the Köhler equation (O'Dowd et al., 2004). In the Köhler model analysis presented here it has been shown that, notwithstanding the moderate reduction of the surface tension at activation produced by marine organics, this effect is too low to compensate for the impact on the Raoult term and lead to an enhancement of the cloud activation activity of the particles. In a companion paper (Fuentes et al., 2010b) it was shown that the production of particles with $D_{p 0}<100 \mathrm{~nm}$ was increased in a $20-40 \%$, due to presence of the diatomaceous exudate in seawater (Fuentes et al., 2010b). On the other hand, in the experiments conducted in the present study, a 5-24\% reduction in the CCN activity of the particles occurred due to the incorporation of marine organics into the composition of the primary marine aerosol. This leads to the enhancement of the CCN formation potentially induced by the biological production (due to an the increase in the particle production) (Fuentes et al., 2010b) being counteracted by the reduction of the $\mathrm{CCN}$ activity produced by the marine organics.

Similar CCN behaviour to that found in this work has been observed in other studies on the effect of organic biomolecules (Kristensson, 2010) and marine organic extract (Moore et al., 2008) on the activation behaviour of mixed particles. The marine aerosol produced from solutions of sulphate salts and marine organics $<0.45 \mu \mathrm{m}$ has been shown to present less or equal cloud formation activity than ammonium sulphate (Moore et al., 2008), while the replacement of inorganic salt by increasing amount of aminoacid compounds has been found to lead to particles with decreasing CCN activity (Kristensson, 2010).

In the present study marine organic matter $<0.2 \mu \mathrm{m}$ has been used; thus, further research is needed in order to determine whether the observed behaviour extrapolates to large colloids in the size range above $>0.2 \mu \mathrm{m}$, or indeed, whether such colloids play a role in particles of the smaller sizes where organics are most substantially enriched. Predictions using the Köhler theory indicate that for organic mass fractions $\sim 50 \%$ and a mean molar mass $\geq 2 \mathrm{kDa}$, the surface tension at the point of activation should be less than $55 \mathrm{mN} / \mathrm{m}$ for the primary particles to be more $\mathrm{CCN}$ active than pure $\mathrm{NaCl}$ and, thereby, attribute the enhancement of cloud formation in algal bloom areas observed by Meskhidze and Nenes (2006) to the primary organic matter. Even in the event that the organic pool $>0.2 \mu \mathrm{m}$ would lead to organic fractions higher than those observed in the present study, it is unlikely that the droplet surface tension at the diluted conditions that characterise the point of activation presents such a low value. Thus, it is questionable that primary marine organics are responsible for the increased cloudiness evident in high biological activity areas.

\section{CCN closure: hygroscopicity parameter $\kappa$}

Based on the measurement data, the $\kappa$-Köhler model (Petters and Kreidenweis, 2007) was employed in order to analyse whether the single parameter approach can be used to link the 

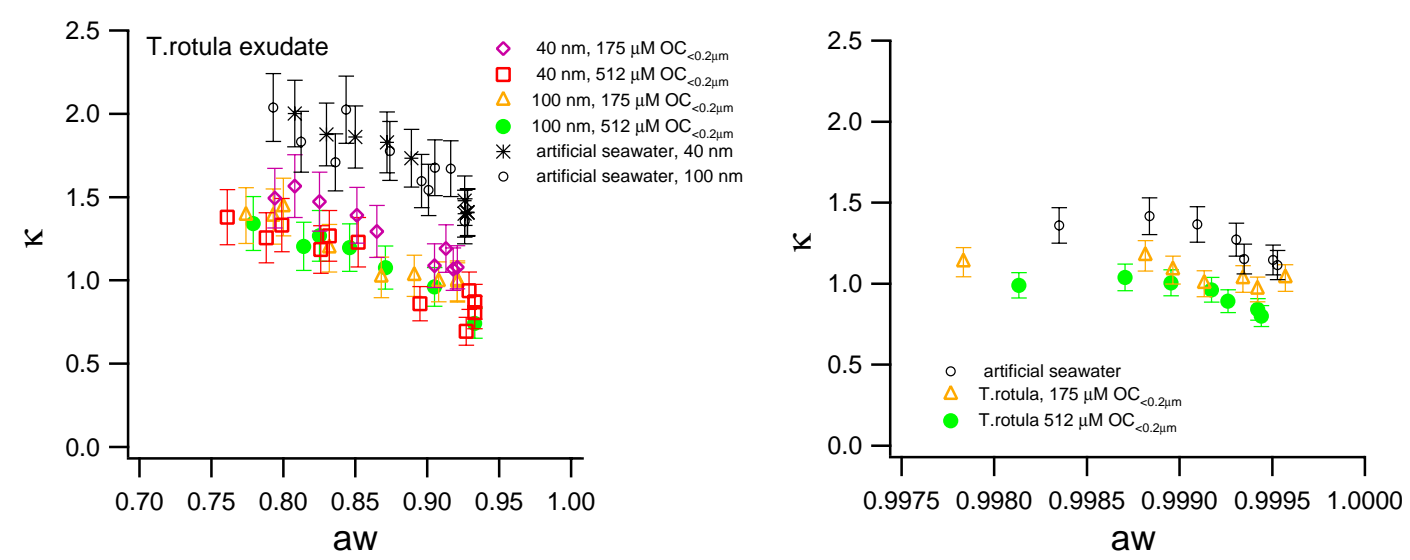

Fig. 11. Hygroscopic parameter $\kappa$ in the sub- and supersaturated regions for primary marine aerosol produced from artificial seawater devoid of exudate and seawater proxies enriched with $T$. rotula exudate.

sub-saturated hygroscopicity and cloud condensation activity of the primary marine aerosol.

According to the $\kappa$-Köhler theory (Petters and Kreidenweis, 2007) the water activity can be defined as a function of the parameter $\kappa$ as:

$a_{\mathrm{w}}=\frac{D^{3}-D_{p}^{3}}{D^{3}-D_{p}^{3}(1-\kappa)}$

where $D_{p}$ is the particle dry diameter.

The relative humidity in the humidograms can be converted to $a_{\mathrm{w}}$ values by using the Kelvin term defined in Eq. (7), and the $\kappa$ parameter can be derived by rearranging Eq. (9) as follows:

$\kappa=\frac{\left(\mathrm{GF}^{3}-1\right)\left(1-a_{\mathrm{w}}\right)}{a_{\mathrm{w}}}$

For the prediction of $\kappa$ from the $\mathrm{CCN}$ measurements an expression of the saturation ratio can be derived by combining Eqs. (7) and (9) as:

$S=\frac{D^{3}-D_{p}^{3}}{D^{3}-D_{p}^{3}(1-\kappa)} \exp \left(\frac{4 \sigma_{\mathrm{s}} M_{\mathrm{w}}}{\rho_{\mathrm{w}} R T D_{p}}\right)$

The value of the parameter $\kappa$ in the above expression is obtained by fitting the maximum of the curve to the experimental value of critical supersaturation. For ideal solutions, $\kappa$ is a constant that depends only on the solute properties. Deviations from the ideal behaviour causes $\kappa$ to be dependent on the water activity, thus leading to inconsistency in the value of $\kappa$ in the sub- and supersaturation regimes. In order to evaluate the deviation from the non-ideal behaviour, the $\kappa$ Köhler model was applied using the HTDMA and CCN data obtained in this work. For the analysis, the surface tension was calculated by using the Szyskowski-Langmuir isotherms presented in Sect. 3.5. Figure 11 shows the calculated values of $\kappa$ as a function of the water activity in the sub- and supersaturation regions, for the primary marine aerosol generated from artificial seawater and from seawater enriched with $E$. huxleyi exudate. In the subsaturation region, it is observed a systematic non-ideal behaviour characterised by a drop of the value of $\kappa$ with increasing water activity for all the cases tested. In the supersaturation region, on the other hand, the value of $\kappa$ shows lower dependency on the water activity. Similar results were obtained for the rest of the organic exudates (Fig. S5). Our data are consistent with findings in Wex et al. (2010), within the range of uncertainty of the measurements of the cited work. However, in our results it can also be appreciated a dependence of the hygroscopic parameter on the water activity in the subsaturated region. Notwithstanding the different behaviour of $\kappa$ in the sub- and supersaturated regions, the deviations of subsaturated $\kappa$ at high humidity and the supersaturated $\kappa$ seems to be small, which could allow the use of the $\kappa$-Köhler model to predict the critical supersaturation from the subsaturated $\kappa$ value at high water activities. In order to test this hypothesis, the experimental critical supersaturations and those derived from the subsaturated $\kappa$ ( $\left.\kappa_{\text {HTDMA }}\right)$ in the range $a_{\mathrm{w}}>0.9$ were compared.

Figure 12 presents the critical supersaturation values derived from the average $\kappa_{\text {HTDMA }}$ at $a_{\mathrm{w}}>0.9$ in comparison with the cloud activation experimental data. This comparison indicates that the critical supersaturations predicted from the hygroscopicity measurements deviate $<5 \%$ with respect to those observed in the $\mathrm{CCN}$ experiments. The conducted analysis yields deviations between the experimental data and predicted critical supersaturation within the uncertainty limits. The single parameter approximation is therefore adequate to link the sub-saturated hygroscopicity and cloud condensation activity of the primary marine aerosol, when considering subsaturated $\kappa$ values between $0.9<a_{\mathrm{w}}<0.92$. 


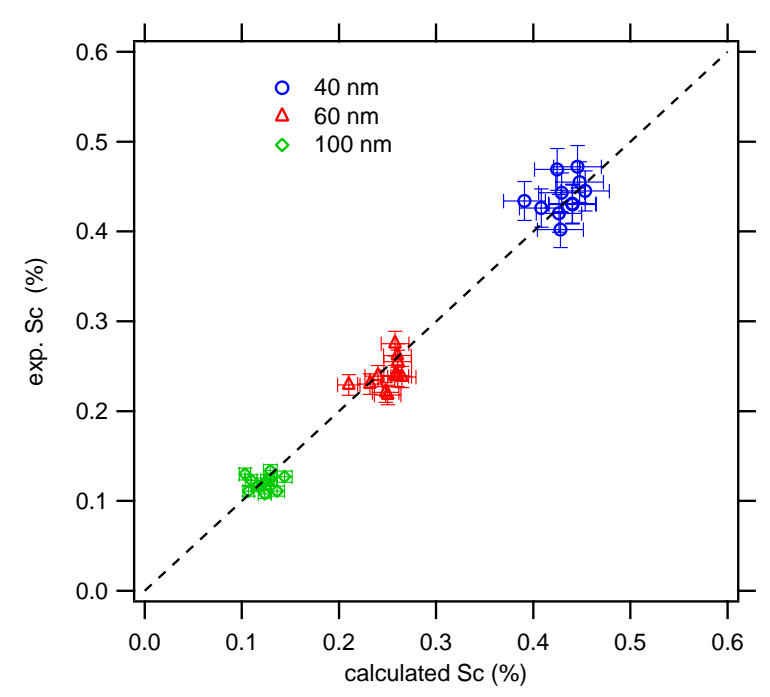

Fig. 12. Comparison of experimental and theoretical critical supersaturations derived using the $\kappa$-Köhler approach in the supersaturated region and in the subsaturated region with $0.9<a_{\mathrm{W}}<0.92$.

\section{Summary and conclusions}

In this study, the role of organic micro- and nanogel colloidal matter plus truly dissolved organic matter $<0.2 \mu \mathrm{m}$ on the properties and composition the primary marine aerosol was investigated.

Marine organic matter produced reductions of $9-17 \%$ and $5-24 \%$ in the hygroscopic growth and cloud condensation activity of the primary marine aerosol, respectively, compared to the production from seawater devoid of marine organics. The effects were enhanced with increasing seawater organic content and the highest influence was observed for the particles generated from seawater enriched with diatomaceous exudate, particularly, the Chaetoceros exudate.

Predictions using the ZSR rule yielded particle organic volume fractions between 8 and $37 \%$ for seawater enriched with $175-512 \mu \mathrm{M} \mathrm{OC}<0.2 \mu \mathrm{m}$. The highest particle organic enrichment was found for the particles generated from diatomaceous exudate. The suppression of the growth factor in the present study is from the order to $15 \%$ higher than the water uptake reductions observed in previous studies on the hygroscopicity of primary marine aerosol generated by bubble bursting from unfiltered natural seawater (Sellegri et al., 2008). The organic content in the generated particles was, however, significantly lower than the organic mass fraction determined in studies on the chemical composition of the submicron primary marine aerosol produced by bubble bursting (Facchini et al., 2008). It has been demonstrated in this work that the particle organic enrichment depends on the seawater organic concentration. Discrepancy between different studies might therefore be explained by the organic content of the source seawater employed together with the mechanism of particle production. The concentration of colloidal matter $\mathrm{OC}_{<0.2 \mu \mathrm{m}}$ in surface waters has been found to vary by a factor of up to 4.5 , depending on the location (Wells and Goldberg , 1993), thus it is expected to find diverging organic enrichment in particles generated from different source seawater.

The increase in the $\mathrm{CCN}$ production observed in algal bloom areas (Meskhidze and Nenes, 2006) has been postulated to be induced by the incorporation of biogenic organics into the composition of the primary aerosol, due to the potential suppression of the surface tension of the particles (O'Dowd et al., 2004). In contrast to this hypothesis, the results in the present work show that the colloidal organic pool $<0.2 \mu \mathrm{m}$ released by phytoplankton reduces the cloud condensation activity of the particles, with respect to the case of seawater without algal exudate. In agreement with observations, theoretical analysis using the Köhler model predicts an increase in the critical supersaturation of the primary particles upon the incorporation of marine organics $<0.2 \mu \mathrm{m}$ into the particle composition. This effect is due the replacement of inorganic salt by large molar mass organic molecules, which leads to the dominance of the solute effect on the Raoult term over the surface tension effect in the Kelvin term.

In a companion paper to this study (Fuentes et al., 2010b) it was shown that the production of particles with $D_{p 0}<100 \mathrm{~nm}$ was enhanced by the presence of diatomaceous exudate in seawater. The results in the present manuscript indicates that, although the $\mathrm{CCN}$ activity could be enhanced due to an increase in the particle production in diatom blooms, this effect would be counteracted by the reduction in the CCN activity induced by the presence of marine organics in the primary particles. Predictions using the Köhler theory indicate that for organic mass fractions $\sim 50 \%$ and mean molar mass $\geq 2 \mathrm{kDa}$, the surface tension at the point of activation should be less than $55 \mathrm{mN} / \mathrm{m}$ for the primary particles to be more $\mathrm{CCN}$ active than pure inorganic seasalt and, thereby, attribute the enhancement of cloud formation in algal bloom areas to the effect of the biogenic organic matter. Even in the event that the organic pool $>0.2 \mu \mathrm{m}$ would lead to organic fractions higher than those observed in the present study, it is unlikely that the droplet surface tension at the diluted conditions that characterise the point of activation exhibits such a low value. Thus, it is improbable that primary marine organics are responsible for any increased cloudiness evident in high biological activity areas. Secondary aerosol formation occurring during high biological activity periods (Charlson et al., 1987; Meskhidze and Nenes, 2006) as well as other factors enhancing the production of cloud-forming aerosol, like wind speed and temperature, and their interactions, should also be investigated as possible causes contributing to the enhancement of cloudiness observed in algal bloom areas.

Analysis using the $\kappa$-Köhler model revealed non-ideal behaviour of the primary marine aerosol at subsaturation, with lower dependence of the hygroscopicity parameter on the water activity in the supersaturated regime. However, 
predictions of critical supersaturation from the hygroscopicity measurements agreed with the experimental values within the range of uncertainty when the subsaturated $\kappa$ was averaged in the range of humidities between 0.9-0.92. The current study is focused only on the colloidal nanogel and truly dissolved organic matter remaining after $0.2 \mu \mathrm{m}$ filtration. Further research should be conducted to analyse the effect of colloidal matter $>0.2 \mu \mathrm{m}$ in order to fully characterise the impact of marine organics on the primary marine aerosol properties.

\section{Supplement related to this article is available online at: http://www.atmos-chem-phys.net/11/2585/2011/ acp-11-2585-2011-supplement.pdf.}

Acknowledgements. This work was supported by the UK Natural Environment Research Council [grant numbers NE/D005175/1 and NE/G000247/1].

Edited by: R. Volkamer

\section{References}

Alfarra, M. R., Paulsen, D., Gysel, M., Garforth, A. A., Dommen, J., Prévôt, A. S. H., Worsnop, D. R., Baltensperger, U., and Coe, H.: A mass spectrometric study of secondary organic aerosols formed from the photooxidation of anthropogenic and biogenic precursors in a reaction chamber, Atmos. Chem. Phys., 6, 52795293, doi:10.5194/acp-6-5279-2006, 2006.

Aluwihare, L. I. and Repeta, D. J. A.: comparison of the chemical characteristics of oceanic DOM and extracellular DOM produced by marine algae, Mar. Ecol. Prog. Ser., 186, 105-117, 1999.

Álvarez-Salgado X. A. and Miller A. E. J.: Simultaneous determination of dissolved organic carbon and total dissolved nitrogen in seawater by high temperature catalytic oxidation: conditions for precise shipboard measurements, Mar. Chem., 62, 325-333, 1998.

Barger, W. R. and Means, J. C.: Clues to the structure of marine organic material from the study of physical properties of surface films, edited by: Sigleo, A. C. and Hattori, A., Marine and Estuarine Chemistry, Lewis Publishers, Chelsea, 47-67, 1985.

Bertilsson, S., Berglund, O., Pullin, M. J., and Chisholm, S. W.: Release of dissolve organic matter by Prochlorococcus, Vie et Milieu, 55(3-4), 225-231, 2005.

Cavalli, F., Facchini, M. C., Decesari, S., Mircea, M., Emblico, L., Fuzzi, S., Ceburnis, D., Yoon, Y. J., O’Dowd, C. D., Putaud, J. P., and Dell'Acqua, A. J.: Advances in characterisation of size resolved organic matter in marine aerosol over the North Atlantic, Geophys. Res., 109, doi:10.1029/2004JD005137, 2004.

Ceburnis, D., O’Dowd, C. D., Jennings, G. S., Facchini, M. C., Emblico, L., Decesari, S., Fuzzi, S., and Sakalys, J.: Marine aerosol chemistry gradients: Elucidating primary and secondary processes and fluxes, Geophys. Res. Lett., 35, L07804, doi:10.1029/2008GL033462, 2008.

Charlson, R. J., Lovelock, J. E., Andreae, M. O., and Warren, S. G.: Oceanic phytoplankton, atmospheric sulphur, cloud albedo and climate, Nature, 326, 655-661, 1987.
Cruz, C. N. and Pandis, S. N.: Deliquescence and hygroscopic growth of mixed inorganic-organic atmospheric aerosol, Environ. Sci. Technol., 34(20), 4313-4319, 2000.

de Leeuw, G. and Cohen, L. H.: Bubble size distributions on the North atlantic and North Sea. Geophysical monograph, Am. Geo. Union, 127, 271-277, 2002.

Dinar, E., Mentel, T. F., and Rudich, Y.: The density of humic acids and humic like substances (HULIS) from fresh and aged wood burning and pollution aerosol particles, Atmos. Chem. Phys., 6, 5213-5224, doi:10.5194/acp-8-6365-2006, 2006.

Facchini, M. C., Mircea, M., Fuzzi, S., and Charlson, R. J.: Comments on Influence of soluble surfactant properties on the activationof aerosol particles containing inorganic solute, J. Atmos. Sci., 58, 1465-1467, 2001.

Facchini, M. C., Rinaldi, M., Decesari, S., Carbone, C., Finessi, E., Mircea, M., Fuzzi, S., Ceburnis, D., Flanagan, R., Nilsson, E. D, de Leeuw, G., Martino, M., Woeltjen, J., and O'Dowd, C. D.: Primary submicron marine aerosol dominated by insoluble organic colloids and aggregates, Geophys. Res. Lett., 35, L17814, doi:10.1029/2008GL034210, 2008.

Frew, N. M. and Nelson, R. K.: Scaling of marine microlayer film surface pressure-area isotherms using chemical attributes. J. Geophys. Res. 97, 5291-5300, 1992.

Fried, J. R.: Polymer science and technology. Chapter 3: Conformation, solutions and molecular weight, Prentice-Hall, Upper Saddle River, New Jersey, USA, 2nd edition., 2003.

Fuentes, E., Coe, H., Green, D., de Leeuw, G., and McFiggans, G.: Laboratory-generated primary marine aerosol via bubblebursting and atomization, Atmos. Meas. Tech., 3, 141-162, doi:10.5194/amt-3-141-2010, 2010a.

Fuentes, E., Coe, H., Green, D., de Leeuw, G., and McFiggans, G.: On the impacts of phytoplankton-derived organic matter on the properties of the primary marine aerosol -Part 1: source fluxes, Atmos. Chem. Phys., 10, 9295-9317, doi:10.5194/acp-10-92952010, 2010b.

Good, N., Coe, H., and McFiggans, G.: Instrumentational operation and analytical methodology for the reconciliation of aerosol water uptake under sub- and supersaturated conditions, Atmos. Meas. Tech., 3, 1241-1254, doi:10.5194/amt-3-12412010, 2010.

Gysel, M., Weingartner, E., Nyeki, S., Paulsen, D., Baltensperger, U., Galambos, I., and Kiss, G.: Hygroscopic properties of water-soluble matter and humic-like organics in atmospheric fine aerosol, Atmos. Chem. Phys., 4, 35-50, doi:10.5194/acp-4-352004, 2004.

Hoffman, E. J. and Duce, R. A.: Organic carbon in marine atmospheric particulate matter: concentration and particle size distribution, Geophys. Res. Lett., 4(10), 449-452, doi:10.1029/GL004i010p00449, 1977.

Keene, W. C., Maring, H. , Maben, J.R., Kieber, D. J., Pszenny, A. A. P., Dahl, E. E., Izaguirre, M. A., Davis, A.J., Long, M. S., Zhou, X., Smoydzin L., and Sander R.: Chemical and physical characteristics of nascent aerosols produced by bursting bubbles at a model air-sea interface, J. Geophys. Res., 112, D21202, doi:10.1029/2007JD008464, 2007.

Kester, D. R., Duedall, I. W., Conners, D. N., and Pytkowicz, R. M.: Preparation of artificial seawater, Limnol. Oceanogr., 12, 176179, 1967.

Kristensson, A., Rosenorn, T., and Bilde, M.: Cloud Droplet Ac- 
tivation of Amino Acid Aerosol Particles, J. Phys. Chem. A, 114(1), 379-386, doi:10.1021/jp9055329, 2010.

Langmuir, I.: The constitution and fundamental properties of solids and liquids. II. Liquids, Am. Chem. Soc., 39, 1848-1906, 1917.

Li, Z., Williams, A. L., and Rood, M. J.: Influence of soluble surfactant properties on the activation of aerosol particles containing inorganic solute, J. Atmos. Sci., 55, 1859-1866, 1998.

Mårtensson, E. M. , Nilsson, E. D., Cohen, L. H., and de Leeuw, G.: Laboratory simulations and parameterization of the primary marine aerosol production, J. Geophys. Res., 108(D9), 4297, doi:10.1029/2002JD002263, 2003.

Martin, J. H. and Fitzwater, S. E.: Dissolved organic carbon in the Atlantic, Southern and Pacific Oceans, Nature, 356, 699-700, 1992.

McFiggans, G., Alfarra, M. R., Allan, J., Bower, K., Coe, H., Cubison, M., Topping, D., Williams, P., Decesari, S., Facchini, M. C., and Fuzzi, S.: Simplification of the representation of the organic component of atmospheric particulates, Faraday Discussions, 130, 341-362, 2005.

Meskhidze, N. and Nenes. A.: Phytoplankton and cloudiness in the Southern Ocean, Science., 314(5804), 1419-1423, 2006.

Middlebrook, A. M., Murphy, D. M., and Thomson, D. S.: Observation of organic material in individual particles at Cape Grim during the First Aerosol Characterization Experiment (ACE 1), J. Geophys. Res., 103(D13), 16475-16483, 1998.

Mikhailov, E., Vlasenko, S., Niessner, R., and Pöschl, U.: Interaction of aerosol particles composed of protein and inorganic salts with water vapor: microstructural rearrangement and hygroscopic growth, Atmos. Chem. Phys., 4, 323-350, doi:10.5194/acp-4-323-2004, 2004.

Modini, R. L., Harris, B., and Ristovski, Z. D.: The organic fraction of bubble-generated, accumulation mode Sea Spray Aerosol (SSA), Atmos. Chem. Phys., 10, 2867-2877, doi:10.5194/acp10-2867-2010, 2010.

Moore, R. H., Ingall, E. D., Sorooshian, A., and Nenes, A.: Molar mass, surface tension, and droplet growth kinetics of marine organics from measurements of CCN activity, Geophys. Res. Lett., 35, L07801, doi:10.1029/2008GL033350, 2008.

Novakov, T., Corrigan, C. E., Penner, J. E. Chuang, C. C., Rosario, O., and Mayol Bracero, O. L.: Organic aerosols in the Caribbean trade winds: A natural source?, J. Geophys. Res., 102(D17), 21307-21313, doi:10.1029/97JD01487, 1997.

O'Dowd, C. D., Facchini, M. C., Cavalli, F., Ceburnis, D., Mircea, M., Decesari, S., Fuzzi, S., Yoon, Y. J., and Putaud, J.-P.: Biogenically driven organic contribution to marine aerosol. Nature, 431(7009), 676-680, 2004.

O’Dowd, C., Langmann, B., Varghese, S., Scannell, C., Ceburnis, D., and Facchini, M. C.: A combined organic-inorganic sea-spray source function, Geophys. Res. Lett., 35, L01801, doi:10.1029/2007GL030331, 2008.

Owaga, H. and Tanque, E.: Dissolved organic Matter in oceanic Waters, J. Oceanogr., 59, 129-147, 2003.

Peng, C., Chan, M. N., and Chan, C. K.: The hygroscopic properties of dicarboxylic and multifunctional acids: Measurements and UNIFAC predictions, Environ. Sci. Technol., 35 (22), 44954501, 2001.

Pérez, V., Fernandez, E., Maraon, E., Serret, P., and Garcia-Soto, C.: Seasonal and interannual variability of chlorophyll a and primary production in the Equatorial Atlantic: in situ and remote sensing observations. J. Plankton Res., 27, 189-197, 2005.

Petters, M. D., Kreidenweis, S. M., Snider, J. R., Koehler, K. A., Wang, Q., Prenni, A. J., and DeMott, P. J.: Cloud droplet activation of polymerized organic aerosol, Tellus B, 58(3), 196-205, 2006.

Petters, M. D. and Kreidenweis, S. M.: A single parameter representation of hygroscopic growth and cloud condensation nucleus activity, Atmos. Chem. Phys., 7, 1961-1971, doi:10.5194/acp-71961-2007, 2007.

Pogorzelski, S. J. and Kogut, A.: Structural and thermodynamic signatures of marine microlayer surfactant films, J. Sea Res., 49, 347-356, 2003.

Putaud, J. P., Van Dingenen, R., Mangoni, M., Virkkula, A., Raes, F., Maring, H., Prospero, J. M., Swietlicki, E., Berg, O. H., Hillamo, R., and Makela, T.: Chemical mass closure and assessment of the origin of the submicron aerosol in the marine boundary layer and the free troposphere at Tenerife during ACE2, Tellus B, 52, 141-168, 2000.

Raymond, T. M. and Pandis, S. N.: Formation of cloud droplets by multicomponent organic particles, J. Geophys. Res., 108(D15), 4469, doi:10.1029/2003JD003503, 2003.

Shapiro, E. L., Szprengiel, J., Sareen, N., Jen, C. N., Giordano, M. R., and McNeill, V. F.: Light-absorbing secondary organic material formed by glyoxal in aqueous aerosol mimics, Atmos. Chem. Phys., 9, 2289-2300, doi:10.5194/acp-9-2289-2009, 2009.

Sellegri, K., Villani, P., Picard, D., Dupuy, R., ODowd, C., and Laj, P.: Role of the volatile fraction of submicron marine aerosol on its hygroscopic properties, Atmos. Res., 90, 272-277, 2008.

Sorjamaa,R., Svenningsson,B., Raatikainen, T., Henning, S., Bilde, M., and Laaksonen,A.: The role of surfactants in Köhler theory reconsidered, Atmos. Chem. Phys., 4, 2107-2117, doi:10.5194/acp-4-2107-2004, 2004.

Stokes, R. H. and Robinson, R. A.: Interactions in aqueous nonelectrolyte solutions: I. Solute-solvent equilibria, J. Phys. Chem., 70, $21262130,1966$.

Sugimura, Y. and Suzuki, Y.: A high temperature catalytic oxidation method for non-volatile dissolved organic carbon in seawater by direct injection of a liquid sample. Mar. Chem. 24, 105131, 1988.

Swietlicki, E., Zhou, J., Covert, D. S., Hämeri, K., Busch, B., Väkevä, M., Dusek, U., Berg, O. H., Wiedensohler, A., Aalto, P., Mäkelä, J., Martinsson, B. G., Papaspiropoulos, G., Mentes, B., Frank, G., and Stratmann, F.: Hygroscopic properties of aerosol particles in the north-eastern Atlantic during ACE-2, Tellus, 52B, 201-227, 2000.

Topping, D. O., McFiggans, G. B., and Coe, H.: A curved multicomponent aerosol hygroscopicity model framework: Part $2-$ Including organic compounds, Atmos. Chem. Phys., 5, 12231242, doi:10.5194/acp-5-1223-2005, 2005.

Verdugo, P., Alldredge,A. L., Azam, F., Kirchmam, D. L., Passow, U. and Santschi, P. H.: The oceanic gel phase: A bridge in the DOM-POM continuum, Mar. Chem., 92, 67-85, 2004.

Vignati E., Facchini, M.C., Rinaldi, M., Scannell, C., Ceburnis, D., Sciare, J., Kanakidou, M., Myriokefalitakis, S., Dentener, F., and O'Dowd, C. D.: Global scale emission and distribution of sea spray aerosol: sea-salt and organic enrichment, Atmos. Environ., 44, 5, 670-677, 2010.

Wells, M. L. and Goldberg, E. D.: Colloid aggregation in seawater, Mar. Chem., 41, 4, 353-358, 1993. 
Wex, H., Stratmann, F., McFiggans, G., and Topping, D.: The Kelvin versus the Raoult Term in the Khler Equation, J. Atmos. Sci., 65, 4004-4016, 2008.

Wex,H., Fuentes, E.,Tsagkogeorgas, G., Voigtlander, J., Clauss, T., Kiselev, A.,Green, D. Coe,H. McFiggans,G. and Stratmann, F.:The influence of algal exudate on the hygroscopicity of sea spray particles, Adv. Metereol., 2010, 365131, 11 pp., 2010.
Wolf, B. A.: Chain connectivity and conformational variability of polymers: Clues to an adequate thermodynamic description of their solutions, 2 Composition dependence of the FloryHuggins interaction parameters, Macromol. Chem. Phys., 204, 13811390, 2003. 